\title{
Micro-RNA-186-5p inhibition attenuates proliferation, anchorage independent growth and invasion in metastatic prostate cancer cells
}

Dominique Z. Jones ${ }^{1,2,3}$, M. Lee Schmidt ${ }^{1,2}$, Suman Suman ${ }^{1,2}$, Katharine R. Hobbing ${ }^{1,2}$, Shirish S. Barve ${ }^{1,4}$, Leila Gobejishvili ${ }^{1,4}$, Guy Brock ${ }^{5}$, Carolyn M. Klinge ${ }^{6,2}$, Shesh N. Rai ${ }^{2,7}$, Jong Park ${ }^{8}$, Geoffrey J. Clark ${ }^{1,2}$, Rajesh Agarwal ${ }^{3}$ and LaCreis R. Kidd ${ }^{1,2^{*}}$

\begin{abstract}
Background: Dysregulation of microRNA (miRNA) expression is associated with hallmarks of aggressive tumor phenotypes, e.g., enhanced cell growth, proliferation, invasion, and anchorage independent growth in prostate cancer (PCa).

Methods: Serum-based miRNA profiling involved 15 men diagnosed with non-metastatic (stage I, III) and metastatic (stage IV) PCa and five age-matched disease-free men using miRNA arrays with select targets confirmed by quantitative real-time PCR (qRT-PCR). The effect of miR-186-5p inhibition or ectopic expression on cellular behavior of PCa cells (i.e., PC-3, MDA-PCa-2b, and LNCaP) involved the use bromodeoxyuridine (BrdU) incorporation, invasion, and colony formation assays. Assessment of the impact of miR-186-5p inhibition or overexpression on selected targets entailed microarray analysis, qRT-PCR, and/or western blots. Statistical evaluation used the modified t-test and ANOVA analysis.

Results: MiR-186-5p was upregulated in serum from PCa patients and metastatic PCa cell lines (i.e., PC-3, MDA-PCa-2b, LNCaP) compared to serum from disease-free individuals or a normal prostate epithelial cell line (RWPE1), respectively. Inhibition of miR-186-5p reduced cell proliferation, invasion, and anchorage-independent growth of PC-3 and/or MDA-PCa-2b PCa cells. AKAP12, a tumor suppressor target of miR-186-5p, was upregulated in PC-3 and MDA-PCa-2b cells transfected with a miR-186-5p inhibitor. Conversely, ectopic miR-186-5p expression in HEK 293 T cells decreased AKAP12 expression by 30\%. Both pAKT and $\beta$-catenin levels were down-regulated in miR-186-5p inhibited PCa cells.
\end{abstract}

Conclusions: Our findings suggest miR-186-5p plays an oncogenic role in PCa. Inhibition of miR-186-5p reduced PCa cell proliferation and invasion as well as increased AKAP12 expression. Future studies should explore whether miR-186-5p may serve as a candidate prognostic indicator and a therapeutic target for the treatment of aggressive prostate cancer.

Keywords: microRNA, Prostate cancer, miR-186, Serum, AKAP12, $\beta$-catenin, Metastasis

\footnotetext{
* Correspondence: Irkidd01@exchange.louisville.edu

1 Department of Pharmacology and Toxicology, University of Louisville School

of Medicine, Louisville, KY 40292, USA

${ }^{2}$ James Graham Brown Cancer Center, University of Louisville School of

Medicine, Louisville, USA

Full list of author information is available at the end of the article
} 


\section{Background}

Prostate cancer (PCa) is the leading cause of nonmelanoma cancer-related mortality in men in the U.S. [1]. Ninety-one percent of PCa cases are treatable among men diagnosed with localized or regional disease as evidenced by a $100 \% 5$-year survival rate [1]. However, the 5-year survival rate drops to $28 \%$ for those with metastatic $\mathrm{PCa}$ [2]. Although early detection of $\mathrm{PCa}$ has improved, better prognostic biomarkers are urgently needed to refine current detection, prognosis, and clinical management strategies for metastatic PCa [3].

MicroRNAs (miRs or miRNAs) are 17-25 nucleotide short non-coding RNAs that may serve as ideal biomarkers of metastatic PCa for several reasons. First, miRs are stably expressed in tumor tissue and related biological fluids, including serum and plasma [4]. Second, miRs regulate the expression of genes involved in tumor spread including cell proliferation, invasion, migration, angiogenesis, and anchorage-independent growth (reviewed in [5-7]). Third, dysregulation of miRNA corresponds with aggressive $\mathrm{PCa}$ phenotypes including high tumor stage, high Gleason grade, disease recurrence, and biochemical recurrence $[8,9]$. Lastly, serum miRNA profiles may distinguish between aggressive and non-aggressive PCa $[10,11]$.

Dysregulation of miRNAs is associated with physiological changes in tumorigenesis and disease progression in $\mathrm{PCa}$ (reviewed in [12]). The role of miR-186 is cancer type-specific and has oncogenic or tumor suppressor roles. For example, miR-186 expression is upregulated in melanoma, endometrial, pancreatic, esophageal, and cervical cancers, suggesting an oncogenic role in these cancers [13-19]. The predominant form of $\mathrm{miR}-186$ is $\mathrm{miR}-186-5 \mathrm{p}$. The influence of miR-186 expression on tumor cellular behavior (i.e., proliferation, invasion, and anchorage independent growth) has been evaluated in pancreatic [17], bladder [20], ovarian [21], and non-small cell lung cancer (NSCLC) cells [22-27]. MiR-186 acts as a tumor suppressor in NSCLC, since its overexpression reduced cell invasion and migration of NSCLC cell lines in vitro $[23,24,26]$. In contrast, overexpression of miR186 in pancreatic [17] and bladder [20] cancer cells enhanced cellular proliferation, migration, colony formation and anchorage independent growth, implicating an oncogenic role for miR-186 in these cancers. Overexpression of miR-186 also repressed the expression of tumor suppressors, including forkhead box $\mathrm{O} 1$ (FOXO1), Nuclear Receptor Subfamily 5 Group A Member 2 (NR5A2), and protein phosphatase, $\mathrm{Mg}^{2}$ ${ }^{+} / \mathrm{Mn}^{2+}$ dependent $1 \mathrm{~B}(P P M 1 B)$ in endometrial [14], pancreatic [17], and bladder [20] cancer cells, respectively. However, the functional role of miR-186$5 \mathrm{p}$ and its targets in PCa remains unclear [28-32]. One report suggested miR-186 functions as a tumor suppressor miRNA in PCa [30]. The authors observed a down-regulation of miR-186 in five human PCa cell lines versus primary cultured prostate epithelial cells and tumor tissue compared with adjacent normal prostate. However, it is not clear whether they evaluated miR-186-3p or miR-186-5p. Moreover, to our knowledge, there are no published reports on the evaluation of miR-186-5p in PCa patient serum.

The purpose of the current study was to identify differentially expressed miRNAs in serum from PCa patients versus normal controls. In addition, this study sought to characterize the role of miR-186-5p in metastatic PCa cell models. Our findings will aid in the understanding of miR-186-5p's role in metastatic PCa using pre-clinical, human PCa cell lines. Our novel identification of increased miR-186-5p in the serum of metastatic PCa patients and its pro-migration/invasion oncogenic activity in PCa cell lines suggests miR-186-5p may serve as a diagnostic, prognostic and ultimately a therapeutic tool for the effective clinical management of metastatic PCa.

\section{Methods \\ Human serum biospecimens}

Serum samples $(0.5-1 \mathrm{ml})$ were collected from five disease-free controls and 15 men diagnosed with $\mathrm{PCa}$ prior to any therapy. All specimens were obtained from BioServe Biotechnologies Biorepository (Beltsville, MD). PCa patients were diagnosed with tumor stage I $(n=5)$, stage III $(n=5)$, and stage IV $(n=5)$ disease. Deidentified demographic and clinico-pathological data for each patient included age, weight, and body mass index (BMI). There was no follow-up data available for these patients after treatment. Samples were stored at $-80{ }^{\circ} \mathrm{C}$ until further use.

\section{Cell culture}

Human prostate cancer metastatic [PC-3 (ATCC CRL-1435), DU145 (ATCC HTB-81), LNCaP (ATCC CRL-1740), 22Rv1 (ATCC CRL-2505), MDA-PCa-2b (ATCC CRL-2422)], embryonic kidney HEK 293 T (ATCC CRL-3216) and normal prostatic epithelial [RWPE1 (ATCC CRL-11609), RWPE2 (ATCC CRL11610)] cell lines were obtained from American Type Culture Collection (ATCC) (Manassas, VA). Prostate cancer cell lines were cultured in Dulbecco's Modified Eagle's Media (HEK 293 T, DU145), RPMI 1640 (22Rv1, LNCaP), T-media (C4-2B) [33], and Kaighn's modified Ham's F-12 K media (PC3). MDA-PCa-2b cells were grown in F-12 K media supplemented with hydrocortisone (100 pg/ml), EGF (10 ng/ml), and FBS (20\%). Normal prostate epithelial cells (RWPE1, RWPE2) were grown in Keratinocyte-SFM supplemented with bovine pituitary extract (BPE) $50 \mu \mathrm{g} / \mathrm{ml}$ ) and human recombinant epidermal growth factor 
(EGF) $(5 \mathrm{ng} / \mathrm{ml})$. All media was supplemented with $10 \%$ of FBS and $1 \%$ of antibiotic $[10,000$ I.U./ml of penicillin, $10,000 \mu \mathrm{g} / \mathrm{ml}$ of Streptomycin, $25 \mu \mathrm{g} / \mathrm{ml}$ Amphoterricin B\}.

\section{Isolation of miRNAs from serum}

Serum $(250 \mu \mathrm{l})$ obtained from 15 patients and five disease-free individuals was transferred to $1.5 \mathrm{ml}$ nuclease-free tubes. Trizol LS Reagent $(1 \mathrm{ml})$ was added to each sample and shaken for $30 \mathrm{~s}$ (secs) at room temperature. Each sample was spiked with cel-miR-39 ( $2 \mu \mathrm{l}, 1 \mathrm{nM}$, internal miRNA control) and incubated for 5 min (mins). ACS 98\% grade chloroform (200 $\mu$ l per $1 \mathrm{ml}$ of Trizol) was added to each sample, shaken for $15 \mathrm{~s}$, and incubated again for 5 mins. Next, total RNA was isolated from serum using the miRVana microRNA Isolation kit (Thermo Fisher Scientific, Waltham, MA).

\section{miR profiling in serum using Taqman human MicroRNA arrays}

Expression analysis of 377 miRNAs involved the use of Taqman Array Human MicroRNA Pool A Cards v.2 (Thermo Fisher Scientific) that included three endogenous controls (RNU6, RNU44, RNU48) and a non-human related negative control (ath-miR-159a). Micro-RNA profiling was assessed using the Applied Biosystems 7900 Real Time PCR system (Thermo Fisher Scientific). RNA was reverse transcribed into cDNA in a $7.5 \mu \mathrm{l}$ reaction using a TaqMan miRNA Reverse Transcription (RT) Kit and MegaPlex RT Primers (10X) (Thermo Fisher Scientific). Diluted pre-amplified RT products in TE (75 $\mu \mathrm{l}, 0.1 \mathrm{X}, \mathrm{pH} 8.0$ ) were added to a reaction mix [100 $\mu \mathrm{l}$ of Taqman Universal PCR Master Mix (2X)] and dispensed into arrays. miRNA profiles in serum were normalized to the global median comparative threshold (Ct) value for each array (global Ct median value - target $\mathrm{Ct}$ value) using R-programming software. Fold change was calculated with respect to each tumor stage relative to disease-free individuals. After normalization, targets with $\geq 50 \%$ missing Ct values were imputed using k nearest neighbor (kNN) imputation. Differentially expressed serum-based miRNAs in PCa patients were selected for further validation using the following selection criteria: FDR $p$-value $\leq 0.05$ and fold change $\geq 1.5$.

\section{RNA/microRNA isolation from cells and qRT-PCR}

Total microRNA was extracted and purified using the miRVana miRNA Isolation kit according to manufacturer's instructions. RNA $(5 \mu \mathrm{l})$ was converted into cDNA using the MicroRNA Reverse Transcription (RT) kit and specific RT primers (Thermofisher Scientific). Total RNA (500 ng or $1 \mu \mathrm{g}$ ) was reverse transcribed into cDNA using qScriptTM cDNA SuperMix (Quanta Biosciences, Beverly, MA). cDNA from cells was mixed with PerfeCTa
SYBR Green FastMix ROX (Quanta Biosciences, Beverly, MA) or Taqman Universal Mix II No UNG plus specific PCR primers; AKAP12 (Qiagen, Germantown, MD), and TaqMan Assays [miR-106b-5p (Assay \# 000442), miR302b-3p, (Assay \# 000531), miR-520e (Assay \# 001119), miR-342-3p (Assay \# 002260), miR-186-5p (Assay \# 002285), miR-885-5p (Assay \# 002296)] for qPCR using the Step Up Real PCR system (Applied Biosystems, Waltham, MA). Relative expression of mRNA and miRNA was normalized to GAPDH and snoRNA U44 expression and calculated using the $2-\Delta \Delta C t$ method. Experiments were repeated three times and in triplicate.

\section{Validation of serum microRNAs using qRT-PCR}

miRNAs were evaluated within the same cohort of $\mathrm{PCa}$ serum samples using Taqman RT and PCR assays for miRs-106b-5p, -302b-3p, -520e, - 342-3p, - 186-5p, and - 885-5p (Thermo Fisher Scientific). miRNA was detected in the RNA/microRNA Isolation from cells and qRT-PCR sections, as previously described. Relative miRNA expression was calculated using the $2^{-\Delta \Delta C t}$ method and normalized to spiked-in miR-cel-39 (serum).

\section{DNA isolation from cells}

RWPE1 cells were grown to $80 \%$ confluency in growth media. Genomic DNA was isolated from cells using DNeasy Blood and Tissue kit (Cat\# 69504, Qiagen, Valencia, CA). DNA concentrations (260/280 nm) were measured using a Nano Dropper Spectrophotometer.

\section{Plasmid constructs}

To construct the pcDNA-DEST47-miR-186 mimic, the full-length of the miR-186-5p precursor was amplified from human genomic DNA and cloned into the pENTR/ D-Topo vector (ThermoFisher Scientific) with BamHI and NotI restriction enzymes. The primer sequences for miR186-5p were: miR-186-5p forward (5'-GCggatccGAGCC ATGCTTATGCTACTG-3') and miR-186-5p reverse (5' -G CgcggccgcCCAGGTATATGGCA-3').

To construct the pcDNA-DEST47-anti-miR-186, the full-length of anti-sense miR-186-5p amplified from human genomic DNA of RWPE1 cells was cloned into the pENTR/D-Topo vector (Thermo Fisher Scientific) and shuttled into pcDNA-DEST47 mammalian expression vector with BamHI and NotI restriction enzymes. The anti-sense oligonucleotide sequences were: antimiR-186-5p forward (5' CACCGCggatccTGCTTGTAAC TTTCCAAAGAATTCTCTCCTTTTGGGCTTTCTG GTTTTATTTTAAGCCCAAAGGTGAATTTTTTGGG AAGTTTGAGCT-3') and anti-miR-186-5p reverse (5' gcggccGCAGCTCAAACTTCCCAAAAAATTCACCTT TGGGCTTAAAATAAAACCAGAAAGCCCAAAAGG AGAGAATTCTTTGGAAAGTTACAAGCA-3'). Clones 
were verified via DNA sequencing by Eurofins Genomics (Louisville, KY).

\section{miRNA mimic and inhibitor transfection}

Biological effects of aberrant miR-186-5p expression were studied by both stable and transient transfection of pcDNA-DEST47 constructs $(1 \mu \mathrm{g}$ pcDNA-DEST47-miR186-5p, pcDNA-DEST47-anti-miR-186-5p), mimic (33 nM Assay\# MC11753, Cat\# 4464066) and inhibitor (33 nM, Assay\# MH11753, Cat\# 4464084) and respective negative controls (pcDNA-DEST47, NC-mimic Cat\# 4464078, NCinhibitor Cat\# 4464078) from ThermoFisher Scientific in PC-3, MDA-PCa-2b, LNCaP, RWPE1, and HEK 293 T cells. Cells were seeded in $60 \mathrm{~mm}$ dishes and transfected in Opti-MEM reduced serum media using JetPrime reagent (Polyplus Transfection, New York, NY) and/or Superfect reagent (Catalog\# 301305, Qiagen, Valencia, CA) according to manufacturer's instructions, respectively. Stably transfected cells were selected using growth medium containing $800 \mu \mathrm{g} / \mathrm{ml} \mathrm{G} 418$ Sulfate. Stable transfected cell clones were maintained and passaged in culture medium with G418 $(400 \mu \mathrm{g} / \mathrm{ml})$. Cells were harvested for cellular behavior assays (i.e., cellular proliferation, invasion, and colony formation assay) $24 \mathrm{~h}$ post-transfection. Ectopic expression and inhibition of miR-186-5p in total RNA and whole cell protein lysate were confirmed via qRT-PCR.

\section{Human gene expression array}

RNA was extracted from transient and stable transfected PC-3 cells with miR-186-5p inhibitor, RWPE1 cells with miR-186-5p mimic, and corresponding scramble (transient) or empty vector controls (stable) in 3 independent experiments. RNA sample purity and integrity were assessed using the Agilent 2100 Bioanalyzer. RNA (250 ng) was serial diluted and transcribed into cDNA and cRNA. Fragmented and biotin-labeled cRNA $(12 \mu \mathrm{g})$ was subjected to a series of incubation periods and hybridized to Prime View gene microarrays with appropriate poly-A and hybridization controls using the 3'IVT Plus Reagent kit (Cat\# 902416, Affymetrix Inc., Santa Clara, CA), according to the manufacturer's instructions. Each array was washed and stained according to array type. The fluidics protocol FS450_0002 was used to analyze each array via Gene chip scanner (Affy.Command console Version 3.3).

\section{Gene selection}

Aberrant gene expression associated with miR-186-5p modification was identified via microarray analysis. Genes up-regulated in stable miR-186-5p inhibited PC-3 cells and down-regulated in stable miR-186-5p overexpressing RWPE1 cells were identified as potential miR$186-5 p$ targets $( \pm 1.2$ fold change in expression and false discovery rate $p$-value $<0.05)$. Next, potential targets were evaluated based on published reports and in silico databases, including MetaCore, Ingenuity, www.TargetScan.org and the www.microrna.org. Final selection of miR-186-5p targets was based on published reports and www.microrna.org database. The aforementioned miR database used PhastCons (positive value $\geq 0.57$ ) and mirSVR (negative score $\leq-0.1$ ) scoring methods to determine highly conserved miRNAs [12, 34].

\section{BrdU proliferation assay}

Cell proliferation in cells was measured using the Cell Proliferation ELISA 5-bromo-2'-deoxyuridine (BrdU) colorimetric kit (\#11647229001, Sigma Aldrich, St. Louis, MO). Transfected cells $\left(5 \times 10^{3} /\right.$ well $)$ were seeded into a 96-well plate format, incubated at $37^{\circ} \mathrm{C}$ for $24 \mathrm{~h}$ and labeled with BrdU reagent for $24 \mathrm{~h}$. Absorbance readings were taken at $370 \mathrm{~nm}$ and $492 \mathrm{~nm}$ (reference) using a Biotek Synergy HT plate reader and Gen5 version 1.08 software (BioTrek, Winooski, VT). Experiments included experimental groups with six replicates that were repeated at least three times.

\section{Anchorage-independent growth assay}

The influence of ectopic expression and inhibition of miR-186-5p on 2-dimensional colony formation was assessed using an anchorage independent growth assay. In 6 -well plates, $0.7 \%$ agar-growth media solution $(3 \mathrm{ml})$, prepared with sterile $3.5 \%$ agar and $1 \mathrm{X}$ phosphate buffered saline (PBS), was added to each well to form a base layer. Transfected cells $\left(10 \times 10^{3}\right)$ in growth media $(3 \mathrm{ml})$ were gently mixed with $0.7 \%$ agar-media solution $(3 \mathrm{ml})$ seeded on top of base layers. Cells in soft agar were incubated at $37{ }^{\circ} \mathrm{C}$ for $2-3$ weeks. Colonies were quantitated at $4 \mathrm{X}$ magnification. Experiments were repeated at least three times.

\section{Matrigel invasion assay}

The effect of miR-186-5p inhibition on cellular invasion was evaluated by the Boyden chamber assay, as described elsewhere (Albini,A. et al. 1987). Briefly, polyethylene transwell inserts with $8 \mu \mathrm{m}$ pore size were coated with a final concentration of $2 \mathrm{mg} / \mathrm{ml}$ of reduced growth matrigel. Cells $\left(25 \times 10^{3}\right)$ were suspended in serum-free media containing reduced growth Matrigel and seeded on top of matrigel. Growth media with FBS $(600 \mu \mathrm{l})$ was added to the lower chamber of each well. After $24 \mathrm{~h}$ of incubation $\left(37{ }^{\circ} \mathrm{C}, 5 \% \mathrm{CO} 2\right)$, non-invading cells on the upper side of the membrane were removed with $1 \mathrm{X}$ PBS. Invading cells were fixed in 100\% methanol and stained with $0.2 \%$ crystal violet. The number of invading cells was counted under a microscope (EVOS) quantified using a 10X magnification. Assays were repeated at least three times. 


\section{Western blot analysis}

Whole cell protein lysates were collected from transiently transfected HEK 293 T, MDA-PCa-2b and PC-3 cells 24$96 \mathrm{~h}$ post-transfection using Radio-Immunoprecipitation Assay (RIPA) buffer (Cat \#R0278, Sigma Aldrich, St. Louis, MO) supplemented with $100 \mathrm{mM}$ sodium orthovanadate and protease inhibitor cocktail (Sigma Aldrich). Protein concentrations were determined using Bradford's assay (Bio-Rad, Hercules, CA). Samples (35 or $45 \mu \mathrm{g}$ ) were separated by MP TGX $4-20 \%$ gels and transferred to PVDF membranes using the Trans-Blot Turbo system (Bio-Rad). Membranes were blocked in 5\% milk for $1 \mathrm{~h}$. AKAP12, $\beta$-catenin, and phospho-AKT were measured using primary monoclonal mouse AKAP12 antibody (1: 500, Sigma Aldrich), primary mouse $\beta$-catenin antibody (1:1000, Cell Signaling, Danvers, MA), monoclonal rabbit phospho-AKT (Ser473) (1:1000, Cell Signaling), secondary anti-mouse antibody (1:10,000, Cell Signaling), secondary anti-rabbit antibody (1:20,000, Cell Signaling) and $\beta$-actin (1:5000, Cell Signaling) as a loading control. Densitometry analysis was performed using ImageJ software (U. S. NIH, Bethesda, MD). Experiments were repeated 2-3 times.

\section{Statistical analysis}

Differences in demographic/clinical data [age, prostate specific antigen (PSA) levels and BMI values] comparing $\mathrm{PCa}$ patients and controls were assessed using the Wilcoxon Rank-Sum test. Differential miRNA expression for each tumor stage was adjusted for multiple hypothesis testing (i.e., FDR) relative to non-cancerous controls using ANOVA and modified $\mathrm{t}$-test with the $\mathrm{R}$ package limma $[35,36]$. Differential gene expression was identified in PC-3 and RWPE1 cells using the Partek Genomics Suite 6.6 software (St. Louis, MO), after adjusting for multiple hypothesis testing using the false discovery test (FDR). MicroRNA/mRNA expression and biological assays were evaluated using two-sided unpaired t-tests. (GraphPad 6 Software, Inc., La Jolla, CA). All statistical significance was established using an alpha cut-off value of 0.05 or $F D R \leq 0.05$. All statistical analysis was performed using GraphPad 6 Software, Inc., (La Jolla, CA).

\section{Results}

\section{Population description}

Serum was collected from 15 PCa patients diagnosed with tumor stage I, III, IV and five disease-free patients who selfidentified as men with European ancestry (Additional file 1: Table S1). There was no significant difference in the median age or BMI levels between cases and controls, respectively. Median PSA levels among cases were significantly higher than non-cancerous controls $(p=0.048)$. Notably PSA levels in controls were higher than the normal range.
According to the clinical data provided for the control biospecimens, each patient was classified as having a normal prostate at the time of serum collection. Although the "control" subjects had high PSA levels, their prostate was designated as disease-free or "normal" based on negative biopsy results. Unfortunately, there was no data on whether the controls had $\mathrm{BPH}$ and there was no available clinical follow-up data for the patients designated as controls. Tumor classification for $60 \%(n=9)$ of the cases were diagnosed with adenocarcinoma and $67 \%$ had a smoking history. However, the smoking history status among the controls was not available for this study population. The majority of the PCa patients received at least two types of therapy $(73.3 \%)$, including hormonal therapy $(n=14,93$. $3 \%)$, radiation $(n=8,53.3 \%)$, surgery $(n=7,46.7 \%)$, and chemotherapy $(n=2,13.3 \%)$.

Differentially expressed miRNAs in the serum of PCa patients We evaluated the expression of 377 miRNAs in the serum from $15 \mathrm{PCa}$ patients diagnosed with tumor stage I $(n=5)$, III $(n=5)$ and IV $(n=5)$ compared to disease-free individuals $(n=5)$. Twenty-six miRNAs were differentially expressed in the serum from $\mathrm{PCa}$ patients $(p \leq 0.05$, fold change $\geq 1.5$ or $\leq-1.5$ ). After adjusting for multiple hypothesis testing, we selected $6 \mathrm{miRs}$ for validation, namely, miRs-106b-5p, -1865p, -302b-3p, - 342-3p, -520e, and - 885-5p (FDR $p$ value $\leq 0.05$ ), as shown in Additional file 2: Table S2. Two miRs $(-106 \mathrm{~b}$ and -186$)$ were validated by qRTPCR. However, we focused on miR-186-5p (FDR $p$ value $=0.005)$ since there were 22 studies on miR$106 \mathrm{~b}$ and prostate cancer but only 4 published reports on the role of miR-186 in PCa [29, 30, 32, 37].

\section{Validation of miR-186-5p in PCa patient serum}

MiR-186-5p expression was validated in two independent experiments within the same cohort of serum samples. MiR-186-5p was significantly upregulated in $\mathrm{PCa}$ serum relative to disease-free individuals (Fig. 1a). To examine its potential role in $\mathrm{PCa}$, miR-186-5p was selected for further validation and characterization using PCa cell lines and normal prostate epithelial cells.

\section{Expression of miR-186-5p in metastatic and non- metastatic PCa cell lines}

MiR-186-5p was significantly higher in metastatic PCa cell lines (LNCaP, MDA-PCa-2b and PC-3) relative to the control RWPE1 cell line (Fig. 1b). Interestingly, miR186-5p expression was highest in metastatic PC-3 cells. However, expression of miR-186-5p did not vary significantly between androgen-sensitive (MDA-PCa-2b, LNCaP, C4-2B) and insensitive (PC-3, DU145) cell lines. miR-186-3p expression was detected at high $\mathrm{Ct}$ values in PCa cell lines (data not shown). 

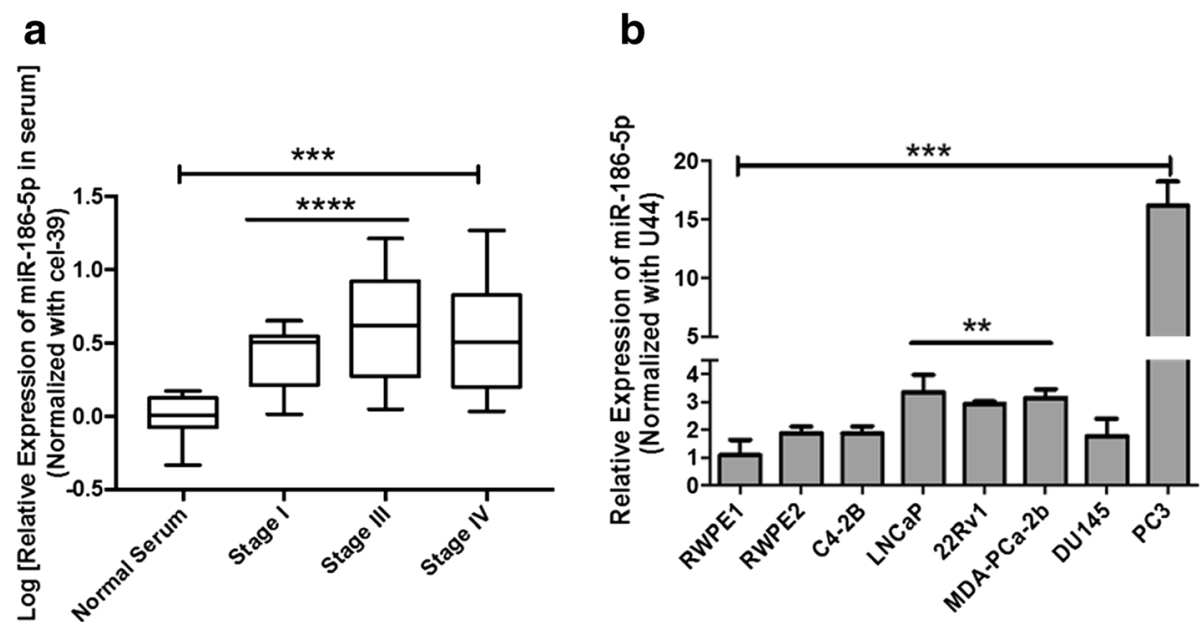

Fig. 1 MiR-186-5p expression in PCa serum and cell lines. a Relative expression of miR-186-5p was validated in two independent isolations of miRNA from PCa serum $(n=15)$ relative to non-cancerous controls $(n=5)$. Elevated levels of miR-186-5p were detected in the serum of patients diagnosed with PCa tumor stage I and III ( $p \leq 0.0001)$, and IV ( $p=0.0007)$ disease. b Relative miR-186-5p expression was measured in normal prostate epithelial cells (RWPE1, RWPE2), prostate carcinoma xenograft (22Rv1), bone (PC-3), lymph node (LNCaP), brain (DU145), and LNCaP - derived bone (C4-2B) metastatic PCa cells using qRT-PCR. MiR-186-5p was up-regulated in four metastatic PCa cell lines (LNCaP, MDA PCa-2b, $P C-3,22 R v 1)$ relative to normal prostate epithelial RWPE1 cells $(p<0.01)$. PC-3 cells exhibited the highest expression among the other cell lines $(p=0.0002)$. Data analyses were based on $2-3$ independent experiments and presented as log [mean fold change] and mean fold change \pm standard deviation (S.D.). (** $p$-value $<0.01$, *** $p$-value $<0.0007$, **** $p$-value $<0.0001$ ) and one-way ANOVA analysis (** $p$-value $<0.005)$

\section{Inhibition of miR-186-5p reduces PCa cell proliferation}

Since miR-186-5p was upregulated in the serum of the metastatic PCa patients, we evaluated the impact of miR-186-5p inhibition on cell proliferation. If miR-186$5 \mathrm{p}$ is oncogenic in PCa cells, we expected inhibition of miR-186-5p would decrease cell proliferation. Indeed, inhibition of miR-186-5p (by transfection of miR-186-5p inhibitor Additional file 3: Figure S1A) reduced cell proliferation by $36 \%$ in metastatic MDA-PCa-2b and slightly (27\%, non-significant) in PC-3 cells (Fig. 2a). Although miR-186-5p expression was upregulated in LNCaP cells (Fig. 1b), inhibition of miR-186-5p did not affect LNCaP cell proliferation (Fig. 2a, Additional file 3: Figure S1A). In contrast, ectopic expression of miR-186-5p (by transfection of a miR-186-5p mimic, Additional file 3: Figure S1B) did not affect PCa proliferation (Fig. 2b).

\section{MiR-186-5p modifies anchorage-independent colony formation in metastatic PCa cell lines}

Previous reports demonstrate miR-186 affects anchorageindependent growth in cancer cells [20,31]. Consequently, we investigated whether inhibition of miR-186-5p alters colony growth of the metastatic PC-3, MDA-PCa-2b, and LNCaP cells. Relative to scramble control, inhibition of miR-186-5p reduced colony formation/anchorage-independent cell growth of PC-3 cells, but not MDA-PCa-2b or LNCaP cells (Fig. 3a, c). Conversely, ectopic expression of miR-186-5p significantly increased colony formation in LNCaP cells, but had no effect on PC-3 or MDA-PCa-2b cells (Fig. 3b, Additional file 3: Figure S1B). These data suggest the impact of miR-186-5p on anchorageindependent cell growth may be saturated in PC-3 cells, perhaps by cell-specific factors that modulate miR-1865 p's stimulation of anchorage-independent cell growth.

\section{Suppression of cell invasion in metastatic PCa}

Since miR-186-5p stimulated anchorage-independent cell growth in PC-3 and LNCaP cells, we evaluated whether inhibition of miR-186-5p affected invasion of metastatic PC-3 and MDA-PCa-2b cells (Figs. 2 and 4a, Additional file 3: Figure S1A). Inhibition of miR-186-5p significantly reduced PC-3 cell invasion, but had no significant effect on MDA-PCa-2b cells (Fig. 4a and b).

\section{Identification of miR-186-5p gene targets}

To identify potential miR-186-5p targets in $\mathrm{PCa}$, gene expression was evaluated in stably miR-186-5p inhibited PC-3 cells and miR-186-5p overexpressed RWPE1 cells (Additional file 3: Figure S1C). After filtering according to the selection criteria $[ \pm 1.2$ fold change, false discovery rate (FDR) $p \leq 0.05]$, microarray analysis identified 1041 direct miR-186-5p targets. Among these potential miR-186-5p targets, 493 were down-regulated in miR-186-5p-overexpressing RWPE1 cells and 547 were upregulated in miR186-5p-inhibited PC-3 cells (Additional file 4: Table S3). Importantly, four previously validated miR-186-5p targets (e.g., AKAP12, ROCK1, PPM1B, and PTTG1) were identified using our microarray analysis coupled with in silico 

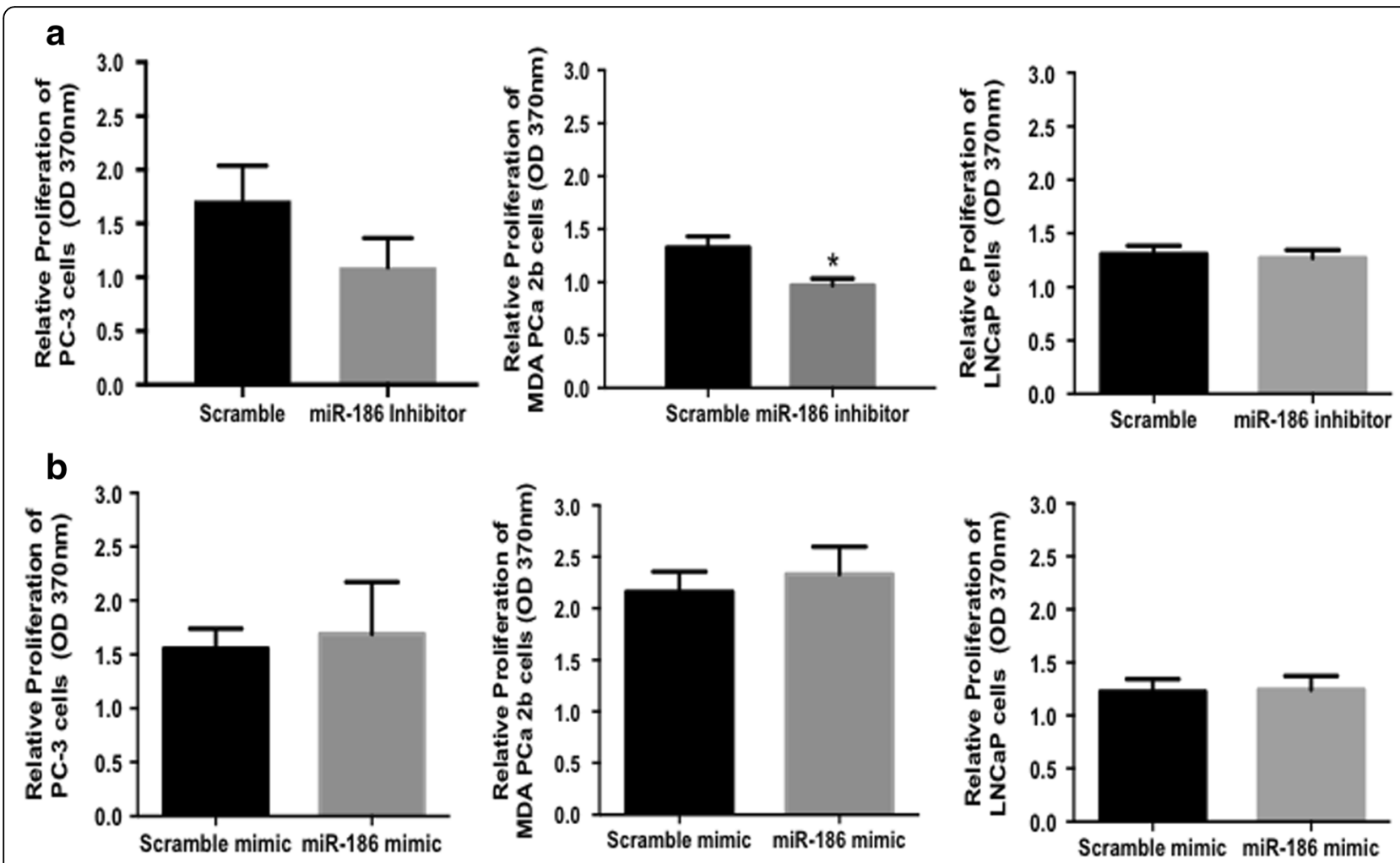

Fig. 2 Inhibition of miR-186-5p reduced MDA-PCa-2b PCa cell proliferation. PCa cells were transiently transfected for 24-48 h with miR-186-5p inhibitor, mimic, and scramble negative controls. Cell proliferation was measured by the BrdU assay. a MiR-186-5p inhibition resulted in a significant decrease in MDA-PCa -2b ( $p=0.013)$ relative to scramble control. b Ectopic miR-186-5p expression did not alter proliferation of PC-3 ( $p=0.6744)$, MDA PCa2b $(p=0.4220)$ and LNCaP ( $p=0.8582)$ relative to scramble control. Data analyses were based on 3 independent experiments and presented as mean absorbance values \pm S.D. $\left({ }^{*} p\right.$-value $\left.<0.02\right)$

tools, i.e., miR Base, microRNA.org, Metacore and Ingenuity Pathway Analysis (Additional file 4: Table S3). Direct target selection using a \pm 2 -fold change cut-off revealed 50 genes (30 targets in PC-3, 20 targets in RWPE1) (Table 1). MiR-186-5p target gene validation was further restricted based on the availability of antibodies for targets. Preference was given to tumor suppressor-related targets based on our results showing oncogenic activity of miR-186-5p in metastatic PCa cell assays (Figs. 2, 3 and 4).

\section{AKAP12 is a direct target of miR-186-5p}

Tumor suppressor targets included A-kinase anchor protein 12 (AKAP12), Tumor Protein P53 (p53, TP53), Forkhead Box O3 (FOXO3), and Phosphatase and Tensin Homolog (PTEN) (Additional file 4: Table S3). AKAP12 was selected for validation given its multifaceted role in cell death, cell proliferation, cell invasion, colony formation and epithelial mesenchymal transition [32]. AKAP12 is a scaffolding protein associated with protein kinases $\mathrm{A}$ (PKA) and $\mathrm{C}$ (PKC). There are three predicted binding sites for miR-186-5p in AKAP12 (Fig. 5a). The three sites were ranked by mirSVR and PhastCons scoring methods. According to PhastCons scoring, binding sites would be ranked in the following descending order: 3 (Score: 0. 6218), 1 (Score: 0.6188) and 2 (Score: 0.5553). However based on mirSVR scoring, the binding sites were ranked in the following ascending order: 2 (Score: - 0.7981), 1(Score: - 0.5641) and 3 (Score: -0.2640 ). Relative to RWPE1 normal prostate epithelial cells, AKAP12 transcript levels were higher in PC-3 cells and lower in LNCaP and MDA-PCa-2b cells (Fig. 5b). We examined whether inhibition of miR-1865p would increase AKAP12 transcript levels in PC-3 cells. Indeed, AKAP12 transcript expression increased in miR186-5p inhibited PC-3 cells (Fig. 5c, Additional file 5: Figure $\mathrm{S} 2 \mathrm{~A})$. This observation suggests $A K A P 12$ is a direct target of miR-186-5p in PC-3 cells.

To further validate AKAP12 as a direct target of miR186-5p, AKAP12 protein expression was examined in HEK $293 \mathrm{~T}$ and PCa cell lysates after transfection with a miR186-5p mimic or a miR-186-5p inhibitor (Fig. 5d, e, g). However, AKAP12 protein expression was not detected in LNCaP cells. Ectopic miR-186-5p expression reduced AKAP12 protein expression in HEK 293 T cells by $30 \%$ (Fig. 5d, Additional file 5: Figure S2B). Inhibition of miR186-5p increased AKAP12 protein expression by $\sim 2$-fold in PC-3 and $~ 1.6$-fold in MDA-PCa-2b cells (Fig. 5e, g). 

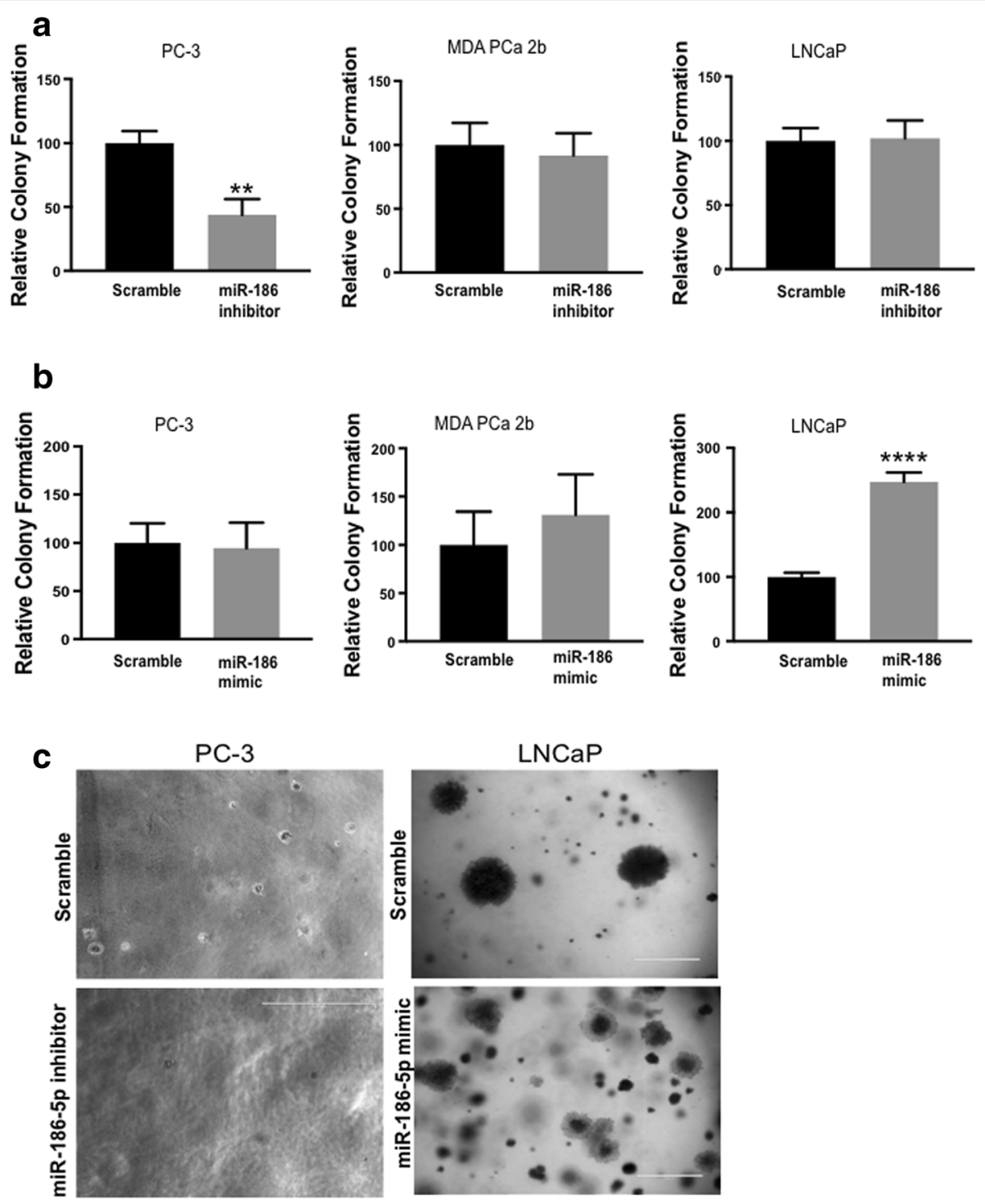

Fig. 3 Alteration of miR-186-5p levels affects PCa cell colony formation. Metastatic PC-3 and MDA-PCa-2b cells were transiently transfected with miR-186-5p inhibitor and mimic for $24 \mathrm{~h}$ and grown in $0.35 \%$ soft agar for $2-3$ weeks at $37^{\circ} \mathrm{C}$. a Inhibition of miR-186-5p reduced PC-3 cell colony formation ( $p=0.0033$ ). $\mathbf{b}$ Ectopic expression of miR-186-5p increased in colony growth in LNCaP cells $(p<0.0001)$. c Representative images of anchorage-independent growth of PC-3 and LNCaP cells transfected with miR-186-5p inhibitor or miR-186-5p mimic, respectively. Data analyses were based on at least 3 independent experiments and presented as mean percentage \pm S.D. $\left({ }^{* *} p\right.$-value $<0.004,{ }^{* * *} p$-value $<0.0001$ )

Inhibition of miR-186-5p reduces pAKT and $\beta$-catenin AKAP12 is a molecular scaffold that interacts with PKA (Protein kinase A), PKC (Protein kinase C), tyrosine kinases, and other plasma membrane receptors [32]. Previous studies reported an increase in phospho-AKT (pAKT) was associated with nuclear accumulation of $\beta$-catenin (CTNNB1) (reviewed in $[31,38])$. Further, knockout of Akap12 in mice resulted in infertility, prostatic hyperplasia, and dysplastic foci and increased pAKT in vivo [39]. Therefore, we examined $\beta$-catenin and pAKT protein expression in scrambled control or anti-miR-186-5p transfected $\mathrm{PC}-3$ and $\mathrm{MDA}-\mathrm{PCa}-2 \mathrm{~b}$ cells relative to appropriate scramble controls (Fig. 5e-h). Inhibition of miR-186-5p significantly reduced $\beta$-catenin protein in MDA-PCa-2b and PC-3 cells (Fig. 5e, g). Similarly, inhibition of miR-186-5p decreased pAKT levels in PC-3 whole cell lysates, but not in MDA-PCa-2b cells (Fig. 5f, h). No change in total AKT was detected in PC-3 and MDAPCa-2b cells transfected with anti-miR-186-5p (Fig. 5f, h). Collectively, the aforementioned data support a pathway by which miR-186-5p inhibition upregulates AKAP12 and decreases $\mathrm{pAKT}$ and $\beta$-catenin in some metastatic $\mathrm{PCa}$ cells, as modeled in Fig. 6. 

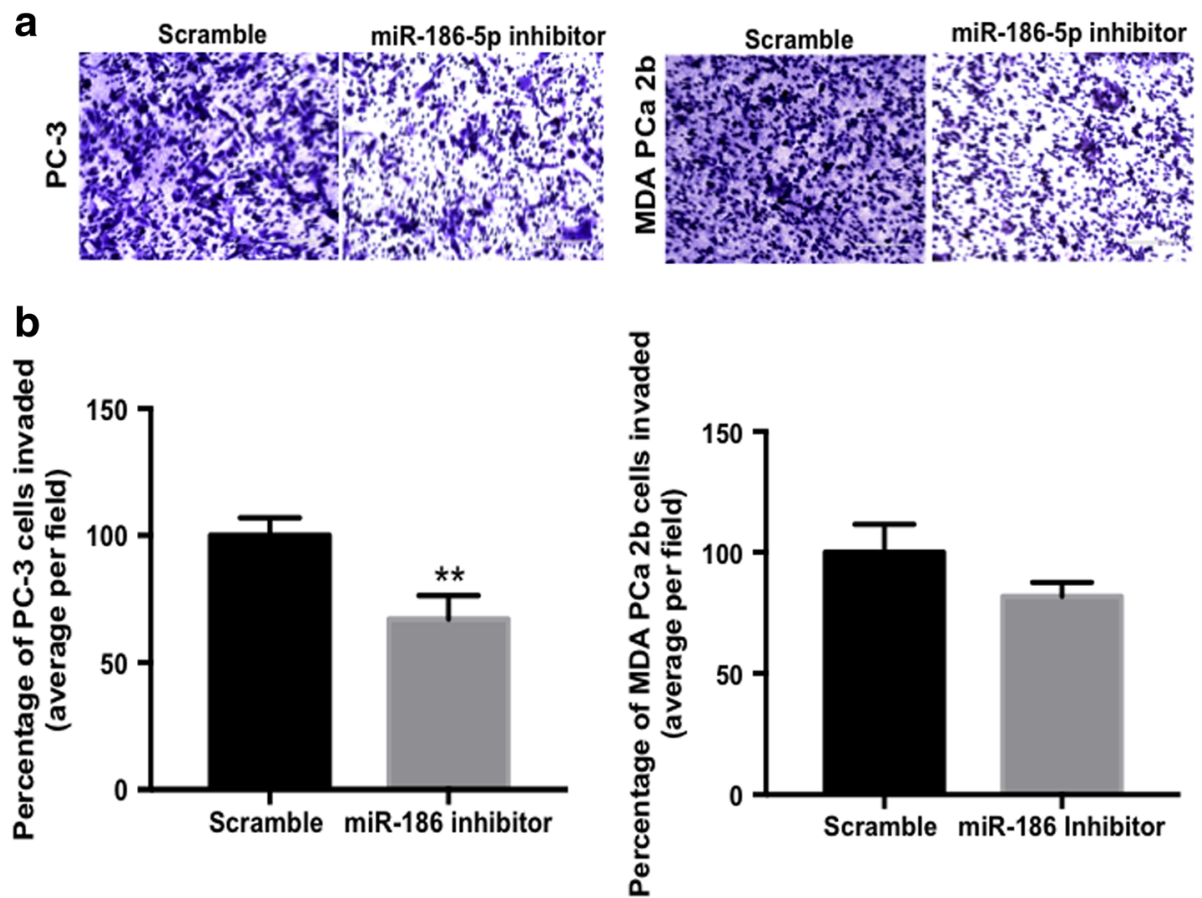

Fig. 4 Inhibition of miR-186-5p reduces metastatic PCa cell invasion. PC-3 and MDA-PCa -2b cells were transiently transfected with scrambled control or miR-186-5p inhibitor for $24 \mathrm{~h}$. Post-transfection, cell invasion through the Matrigel-coated filter was assessed using a transwell assay. a Representative images of PC-3 and MDA-PCa-2b cells after 24 h, 20X magnification. $\mathbf{b}$ Quantification of cell invasion showed the miR-186-5p inhibitor reduced PC-3 invasion $(p=0.008)$. Data were quantitated from at least three independent experiments using an average of four fields of view at $10 \times$ magnification. Data were presented as mean percentage \pm S.D. $(* * p$-value $<0.009)$

\section{Discussion}

Altered miRNA profiles contribute to dysregulation of gene expression involved in the pathogenesis of metastatic PCa [40]. In the current study, we identified upregulation of miR-186-5p in the serum from $\mathrm{PCa}$ patients (tumor stage I, III and IV) and metastatic PCa cell lines (LNCaP, MDA-PCa-2b, PC-3) relative to their respective controls. We also demonstrated inhibition of miR-186-5p reduced PCa cell proliferation, anchorageindependent cell growth, colony formation, and invasion of metastatic PC-3 and/or MDA-PCa-2b cells. Collectively, these findings suggest miR-186-5p plays an oncogenic role in PCa. Indeed, ectopic miR-186-5p expression enhanced anchorage independent growth of LNCaP cells but not PC-3 or MDA-PCa-2b cells.

Whether miR-186 plays a tumor suppressor or oncogenic role in cancer progression may depend on the cancer type and stage of the disease $[13,14,17,20-25,27,29-32,41]$. Some reports suggest miR-186 plays a tumor suppressor role and targets oncogenic-related genes in NSCLC [23, 24], ovarian [21], oral squamous [42], bladder [43], pancreatic [17], multiple myeloma [44], cervical [45], esophageal [46], gastric [47], hepatocellular [48], renal [49], and glioblastoma multiforme [50] cancer cells. In contrast, other reports implicate an oncogenic role for miR-186. For example, in agreement with our data in PCa cells, inhibition of miR-186 decreased cell proliferation and invasion of pancreatic [17], bladder [20], and colon [51] cancer cell lines. It is important to note these studies do not clarify whether they evaluated miR-186-3p or miR-186-5p. However, the current study demonstrated the miR-186-5p form may have an oncogenic role in prostate cancer.

There are limited reports on the role of miR-186 in PCa [28-32, 41]. Commensurate with our serum and in vitro findings, Ambs and colleagues (2008) observed higher miR-186-5p expression in laser microdissected tumor tissue from $\mathrm{PCa}$ patients diagnosed with extra-prostatic disease relative to patients with no extra-prostatic disease among European $(n=30)$ and African American $(n=30)$ men [28]. In contrast, other studies reported miR-186 was down-regulated in non-microdissected $\mathrm{PCa}$ tissue $[30,31]$ and $\mathrm{PCa}$ cell lines, i.e., M12, P69, PC-3, Tsu-Pr1, LNCaP, 22Rv1, DU145 [30-32]. Collectively, these studies suggest a tumor suppressor role for miR-186 in PCa. However, these authors do not distinguish whether the miR-186 precursor, miR-186-5p or miR-186-3p were responsible for apparent cell effects of miR-186 overexpression in PCa cell lines or tissue. Our report suggests miR-186-5p may have an oncogenic role due 
Table 1 Identification of potential miR-186 targets in prostate cancer

\begin{tabular}{|c|c|c|c|c|c|c|c|}
\hline$\overline{C e l l}$ line & Gene & Fold Change & FDR $p$-value & Cell line & Gene & Fold Change & FDR $p$-value \\
\hline \multirow[t]{30}{*}{$\overline{P C-3}$} & PMEPA1 & 6.255 & $8.50219 \mathrm{E}-12$ & RWPE1 & EHF & -6.261 & $2.15476 \mathrm{E}-10$ \\
\hline & FN1 & 5.820 & $5.69038 \mathrm{E}-10$ & & ZNF711 & -4.141 & 1.78879E-09 \\
\hline & TSC22D3 & 4.701 & $1.20663 \mathrm{E}-06$ & & GPC6 & -3.327 & $1.39841 \mathrm{E}-06$ \\
\hline & EFEMP1 & 4.334 & $3.61878 \mathrm{E}-07$ & & FOXG1 & -2.929 & 0.000587093 \\
\hline & EGR1 & 4.130 & $8.19665 \mathrm{E}-07$ & & CPE & -2.769 & 4.23842E-05 \\
\hline & TUBE1 & 3.931 & $1.90071 \mathrm{E}-08$ & & CLCA2 & -2.613 & 0.000051171 \\
\hline & JAG1 & 3.229 & $4.83412 \mathrm{E}-06$ & & CCL20 & -2.581 & $6.13709 \mathrm{E}-05$ \\
\hline & ZNF674 & 2.983 & $8.39119 \mathrm{E}-07$ & & SPX & -2.496 & 4.34943E-07 \\
\hline & SLITRK6 & 2.911 & 6.95917E-06 & & ZFP42 & -2.431 & $3.0742 \mathrm{E}-06$ \\
\hline & PSAT1 & 2.587 & 3.20654E-09 & & AKAP12 & -2.376 & 0.000243387 \\
\hline & KCNT2 & 2.489 & 1.49162E-06 & & ALDH1A2 & -2.321 & 3.93333E-05 \\
\hline & VEGFA & 2.489 & $4.31602 \mathrm{E}-11$ & & HECTD2 & -2.319 & 0.000018492 \\
\hline & CEBPG & 2.472 & 4.43309E-11 & & MCTP1 & -2.239 & 1.89756E-07 \\
\hline & KLF9 & 2.426 & 7.74733E-06 & & APOLD1 & -2.228 & 0.000016442 \\
\hline & WNT5A & 2.426 & $2.56651 \mathrm{E}-07$ & & HMGN5 & -2.183 & 0.000131712 \\
\hline & TRIM36 & 2.403 & 7.29682E-07 & & TPRG1 & -2.182 & 7.81032E-06 \\
\hline & SLC22A15 & 2.399 & $3.03846 \mathrm{E}-05$ & & GPR19 & -2.172 & $3.87728 \mathrm{E}-06$ \\
\hline & CSGALNACT1 & 2.374 & $2.85369 \mathrm{E}-07$ & & BCL11A & -2.145 & $6.80441 \mathrm{E}-05$ \\
\hline & $\mathrm{RHOB}$ & 2.328 & $1.55029 \mathrm{E}-05$ & & GJA3 & -2.036 & 1.67961E-05 \\
\hline & SAT1 & 2.291 & $5.84464 \mathrm{E}-10$ & & BCL2L11 & -2.030 & 4.64641E-05 \\
\hline & MAML3 & 2.288 & 0.000130184 & & & & \\
\hline & ERRFI1 & 2.200 & 1.12777E-10 & & & & \\
\hline & KDM7A & 2.193 & $2.32714 \mathrm{E}-06$ & & & & \\
\hline & ZNF558 & 2.179 & 0.000232804 & & & & \\
\hline & CD55 & 2.121 & $6.2058 \mathrm{E}-07$ & & & & \\
\hline & APOBEC3F & 2.112 & 0.000469815 & & & & \\
\hline & PLEKHG1 & 2.081 & $2.30428 \mathrm{E}-05$ & & & & \\
\hline & MTHFD2 & 2.048 & $3.7309 \mathrm{E}-12$ & & & & \\
\hline & BCL6 & 2.039 & $5.70622 \mathrm{E}-05$ & & & & \\
\hline & C20orf197 & 2.011 & 0.000166965 & & & & \\
\hline
\end{tabular}

Statistical significance was established at a 0.05 significance level

to its up-regulation in the serum of PCa patients and tumor cell lines. The discrepancies between our findings and other miR-186 reports may also be attributed to the following: (1) tumor tissue processing or storage methods; (2) selection of "normal prostate" tissue using microdissected versus non-microdissected tissue; (3) types of "control" cell lines used for comparison purposes; (4) degree of specificity of primers used for quantitation of miR-186-3p or miR-186-5p; (5) selection of normalizer for miRNA quantification; and (6) methods of miRNA isolation and detection. For the detection and semiquantitation of miR-186-5p in the current study, we used normal epithelial cell lines (e.g., RWPE1) for comparison purposes, the miRVana miRNA isolation kit, primers specific for miR-186-5p, and U44 for normalization. In the current study, the U44 levels did not vary among normal epithelial and the prostate cancer cell lines (data not shown). The studies that indicated an tumor suppressor role for miR-186 used: (1) primary culture prostate epithelial cells for comparison purposes with no further details about these cell models; (2) snoRNAs U24, or U6 as controls to normalize miRNA levels; (3) varying kits for miRNA isolation (i.e., Trizol, Qiagen miRNeasy mini kit, E. Z.N.A. miRNA kit); and (4) non-specific rather than specific miRNA primers [30-32]. To our knowledge, the current study is the first to demonstrate the up-regulation of miR-186-5p in serum from PCa patients and in metastatic PCa cell lines. For the serum based studies, we used 
a hsa-miR-186/AKAP12 Alignment

Site 1: 312-338bps

Site 2: $537-561 \mathrm{bps}$

Site 3:961-982bps

hsa-miR-186 3' UCGGGUUUU- CC UC- U -. UAAGAAAC 5'

| : : ||| |||| | | ||||||

AKAP12 5 ' CUUCUGAaACUGGaGUaUCAUUCUUUa 3 '

b

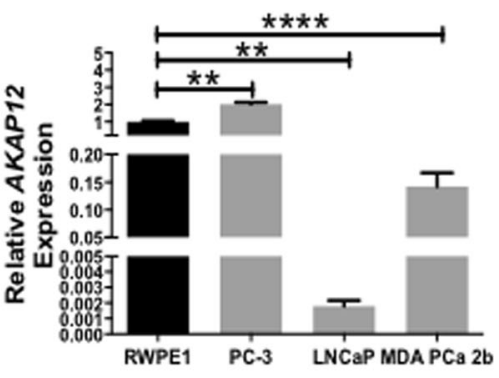

C

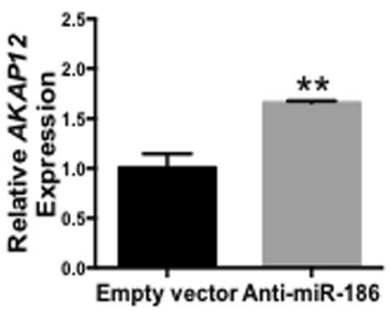

3' UCGGGUU--UUCC-UCUUAAGAAAC 5'

||: : | || || | |||| || ||

5' UuCCUGAUCAAGGUACAAUUCUUUa $3^{\prime}$
3' ucgeguuUuccucuUAAGMAC 5

| | | || ||

5' gccauauuugugccauUCUUUu 3'

d

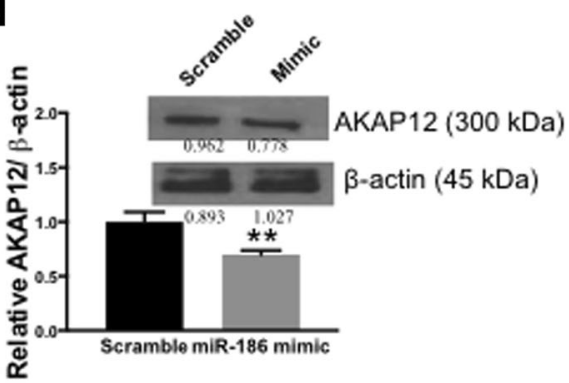

e

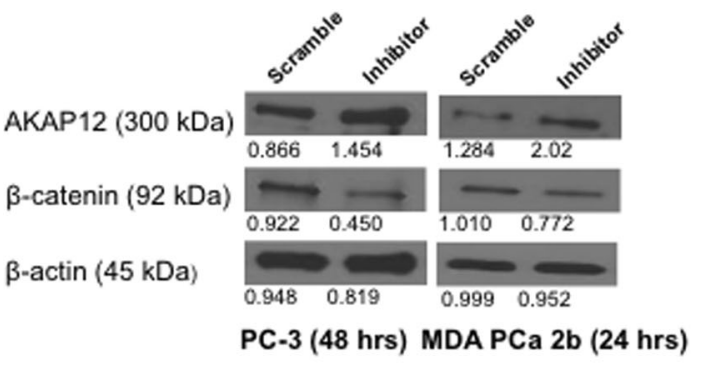

g

Scramble $\square$ miR-186 inhibitor
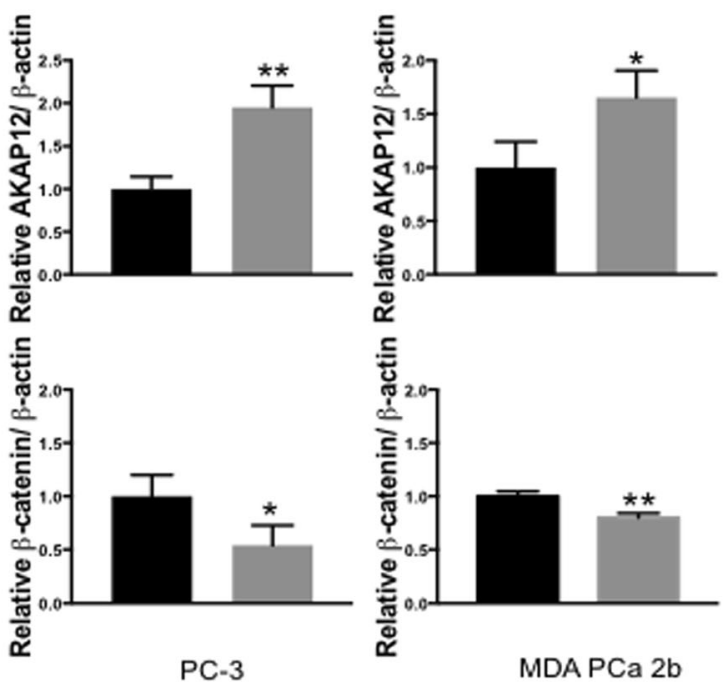

Fig. 5 (See legend on next page.)

f

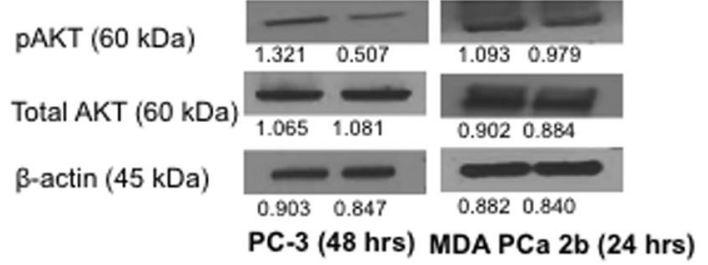

h
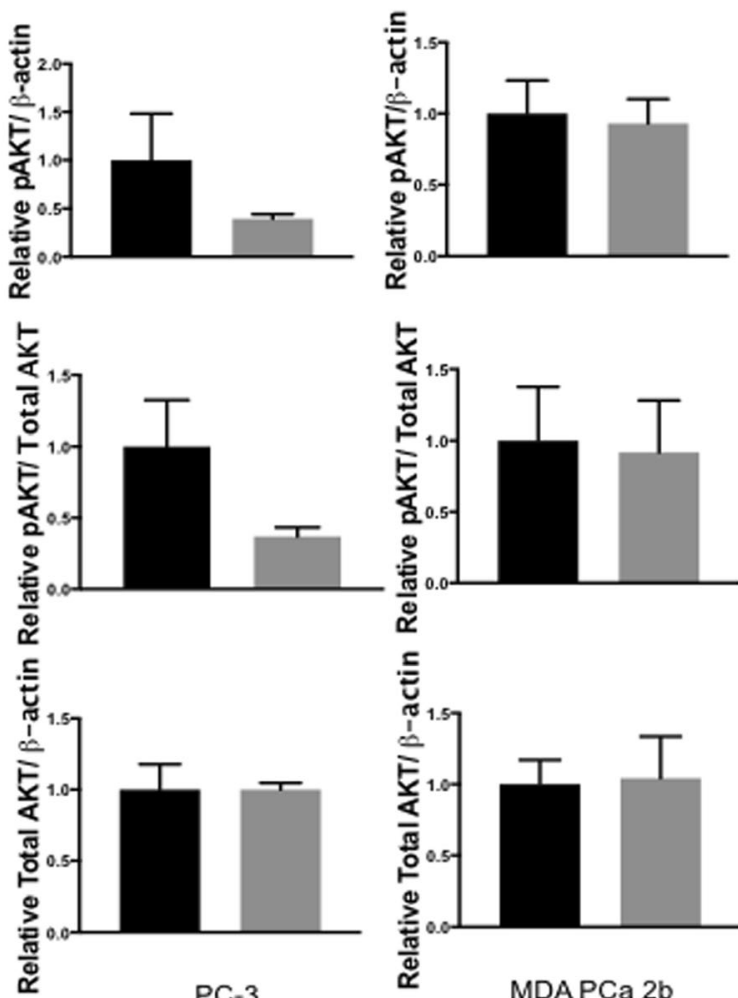

PC-3

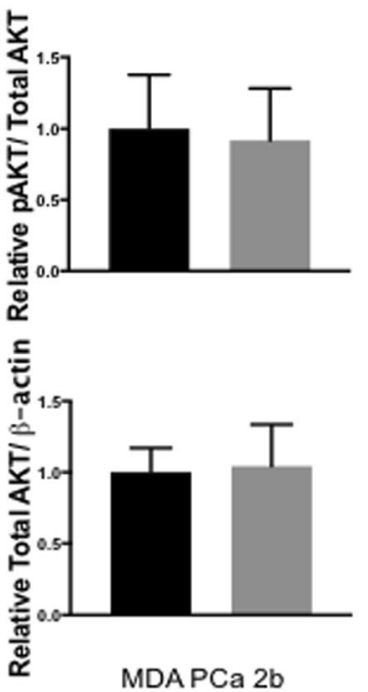




\begin{abstract}
(See figure on previous page.)
Fig. 5 Tumor suppressor AKAP12 is a target of miR-186-5p in PCa cells. AKAP12 transcript and protein expression were measured using qRT-PCR and western blot analysis, respectively. a Three potential miR-186-5p binding sites in AKAP12 were identified; site 1) mirSVR score: - 0.5641 PhastCons score: 0.6188; site 2) mirSVR score: -0.7981 PhastCons score: 0.5553 ; and site 3) mirSVR score: -0.2640 PhastCons score: 0.6218 (values from www.microrna.org). b AKAP12 transcript expression was significantly lower in metastatic LNCaP $(p=0.0011)$ and MDA-PCa-2b $(p<0.0001)$ cells and higher in PC-3 cells relative to normal prostate RWPE1 cells $(p=0.0011)$. c Stable anti-miR-186-5p expression in PC-3 cells increased AKAP12 transcript expression $(p=$ 0.0013). AKAP12 expression was normalized to GAPDH. d HEK 293 T cells were transfected with scrambled miR control or miR-186-5p mimic. A representative western blot shows ectopic expression of miR-186-5p in HEK 293 T cells decreased AKAP12 protein by $30 \% 72 \mathrm{~h}$ post-transfection $(p=$ 0.0063). All analyses involved at least three independent experiments. e and $\mathbf{f}$ Representative western blots of AKAP12, $\beta$-catenin and pAKT expression in HEK 293 T (72 h), PC-3 (48 h), and MDA-PCa-2b (24 h) cells post-transfection. Data analyses included three independent experiments for e and two experiments for $\mathbf{f} . \mathbf{g}$ and $\mathbf{h}$ Quantitation of western blots presented as black bar (scramble control) and grey bar (miR-186-5p inhibitor). AKAP12 protein was increased in PC-3 ( $p=0.0049)$ and MDA-PCa-2b $(p=0.0318)$ cells transiently transfected with miR-186-5p inhibitor. In contrast, $\beta$-catenin/ $\beta$-actin protein was decreased in PC-3 $(p=0.0434)$ and MDA-PCa-2b $(p=0.0048)$ cells transfected with miR-186-5p inhibitor. Data analysis was based on mean \pm S.D. of target protein relative to $\beta$-actin in the same blot. $\left({ }^{*} p\right.$-value $<0.05,{ }^{* *} p$-value $<0.007,{ }^{* * * *} p$-value $<0.002$ )
\end{abstract}

the miRVana isolation kit and an exogenous miRNA control, namely cel-miR-39 (i.e., C. Elegans 39 - a nonhuman miRNA).

We identified miR-186-5p targets using in silico tools followed by functional assays. Among the established miR-186-5p targets, we selected AKAP12 for further evaluation due to its central role in cell proliferation, colony formation, cell invasion and epithelial mesenchymal transition and tumor growth [39, 52-56]. A previous study demonstrated AKAP12 is a bona fide direct target of miR-186-5p using 3'-UTR-luciferase reporter assay [57]. Down-regulation of AKAP12 suppresses cell proliferation, survival, motility, migration, anchorage independent growth, angiogenesis and invasion in several cancers (reviewed in [52]).

Notably, several cancer phenotypes (i.e., cell proliferation, colony formation, invasion) were attenuated upon miR-186-5p inhibition in metastatic PCa cell lines in the current study. This reduction in aggressive PCa behavior may partially correspond with upregulation of AKAP12. Ectopic expression of AKAP12 is associated with a decrease in cell invasion and anchorage independent growth of mouse PCa cells [54, 58]. Furthermore, knockout of AKAP12 in mice resulted in prostatic hyperplasia and dysplastic foci [39], supporting a role of AKAP12 as a tumor suppressor gene.

AKAP12 knockout mice also showed increased expression of pAKT in prostate tissue [39]. pAKT signaling inhibits Glycogen Synthase Kinase-3 (GSK3) activity, which leads to $\beta$-catenin nuclear accumulation [38]. Loss of tumor suppressor PTEN, which is common in PCa, leads to activation of PI3K and AKT signaling and subsequent $\beta$-catenin phosphorylation [59]. Phosphorylation of $\beta$-catenin increases its stability and nuclear localization, which leads to its association with T-cell specific transcription factor/lymphoid enhancer-binding factor 1 family proteins (TCF/LEF-1) in the nucleus. The TCF/LEF-1- $\beta$ catenin complex recruits coactivators such as B-cell lymphoma 9 protein (Bcl-9) and cAMP response element binding protein (CREB)-binding protein (CBP) [60], resulting in an increase in the transcription of genes involved in tumorigenesis, angiogenesis, extracellular matrix, and cell cycle progression, including $M Y C$, $M M P 7, V E G F$, and CCND1 [61, 62].

In addition, $\beta$-catenin is an integral signaling protein for epithelial mesenchymal transition (EMT) and the transcription of genes in the canonical Wnt signaling pathway [38]. Here, we observed inhibition of miR-186$5 p$ resulted in a decrease in $\beta$-catenin protein in PC-3 and MDA-PCa-2b cells. We speculate the repression of the aggressive PCa phenotype observed in miR-186 inhibited PCa cells is partially attributed to AKAP12 mediated down-regulation of pAKT, which in turn, may downregulate $\beta$-catenin (modeled in Fig. 6). Several reports demonstrate pAKT phosphorylates and stabilizes $\beta$ catenin and phosphorylated $\beta$-catenin activates AKT expression [31, 63]. Consequently, we propose an increase in miR-186-5p expression stimulates AKT signaling via decreasing AKAP12, leading to increased nuclear $\beta$-catenin, an EMT mediator. This proposed mechanism may explain the influence of miR-186-5p on cell invasion and anchorage-independent growth in metastatic PCa cell models in the current study. Future studies will validate whether miR-186-5p inhibition down-regulates AKT signaling, allowing GSK3 to promote $\beta$-catenin degradation.

We evaluated the strengths, limitations and future directions of the current study. In a pilot study, our lab was the first to demonstrate the up-regulation of miR-18-5p in the serum of patients diagnosed with non-metastic and metastatic prostate cancer when compared to those without prostate cancer. Although the controls on average had elevated PSA, they were designated as prostate cancer-free at the time of the serum collection, following a biopsy. We cannot exclude the possibility that the controls had benign prostatic hyperplasia. If we assume the controls in the 


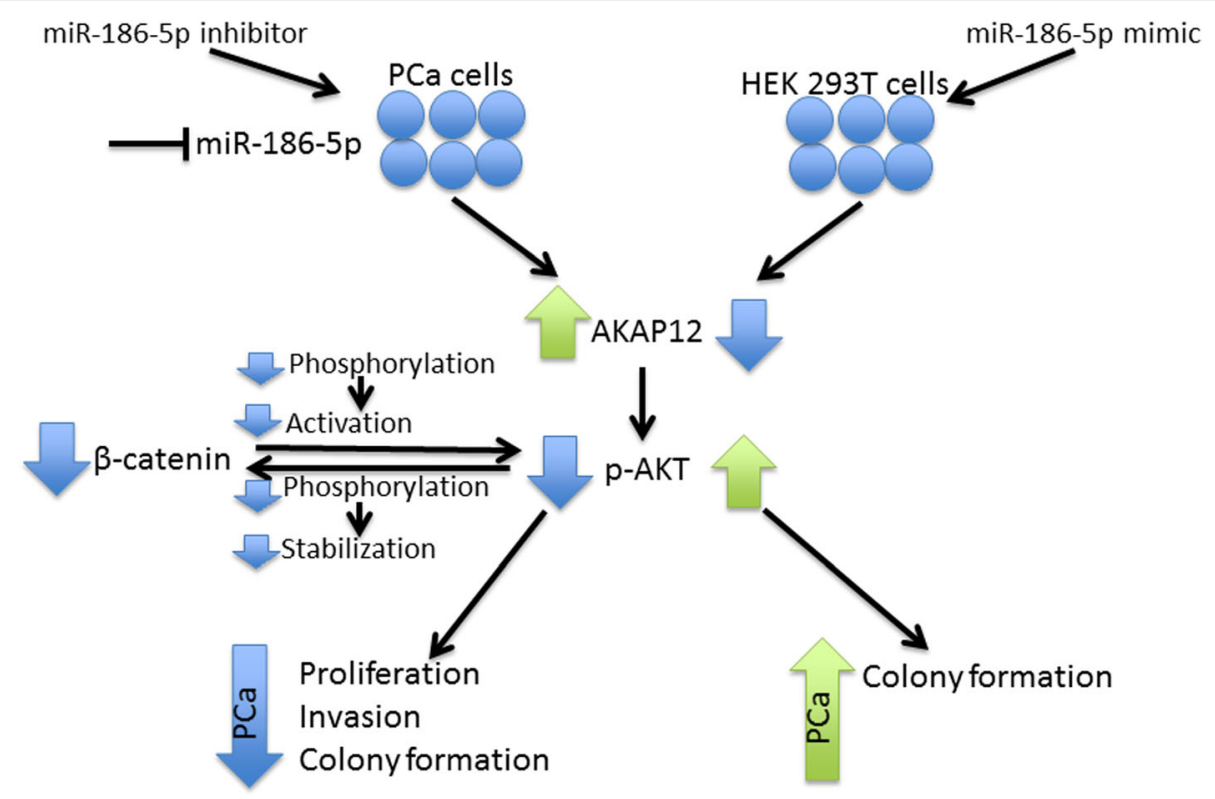

Fig. 6 Model of oncogenic miR-186-5p activity in PCa. Transient inhibition of miR-186-5p resulted in an increase in the tumor suppressor AKAP12 and down-regulation of tumorigenic $\beta$-catenin in PC-3 cells. Inhibition of miR-186-5p resulted in a reduction in pro-survival p-AKT. However, ectopic miR186-5p expression corresponded with an elevation in $\mathrm{p}-\mathrm{AKT}$

current study had $\mathrm{BPH}$, we would anticipate an even higher fold increase serum-based miR-186-5p levels from prostate cancer patients relative to levels among non-BPH controls. Future studies will confirm whether miRNA186-5p detected in serum and matched micro-dissected prostate tumor specimen correspond with high tumor grade/stage, metastatic disease, higher risk of biochem$\mathrm{ical} /$ disease recurrence, or hormone refractory status within large and ethnically diverse patient sub-groups.

Although miR-186-5p was also up-regulated in nonmetastatic and metastatic prostate cancer cell lines, miR-186-5p levels did not vary by androgen receptor status. Interestingly, over-expression of miR-186-5p in PC-3 cell lines did not result in an increase in aggressive prostate cancer cellular behavior. Since the PC-3 cells have the highest expression of miR-186-5p, we believe overexpression of miR-186-5p in PC-3 cells had no further biological effect in these cells. The high baseline levels of miR-186-5p in the PC3 cells may have saturated any biological effects (i.e., cell proliferation, colony formation and cell invasion) and prevented our capacity to detect further aggressive phenotypes in these already transformed cells. However, additional pre-clinical studies are needed to assess whether miR-186-5p overexpression and inhibition alter aggressive tumor behavior in other metastatic PCa cell models (e.g., TSU-Pr1, MDA PCa-2a, VCaP, DuCaP) as well as tumorigenesis in animal models in the presence and absence of androgen stimulation.
To our knowledge, this is the first study to demonstrate AKAP12 as a miR-186-5p target in metastatic PCa cell lines (PC-3, MDA-PCa-2b). Importantly, inhibition of miR-186-5p suppressed three metastatic PCa cell hallmarks, namely proliferation, invasion, and colony growth. We speculate the reduction in cell proliferation, invasion, and anchorage independent growth with anti-miR-186-5p may be attributed, at least in part, to AKAP12's role in pAkt mediated suppression of $\beta$-catenin. Following inhibition/overexpression of miR-186-5p, we demonstrated an up-regulation of tumor suppressor AKAP12 as well as a downregulation pAkT and $\beta$-catenin in vitro in total cell lysates of PC3 cells. Since increased $\beta$-catenin is apparent in many cancers, including prostate cancer $[4,5,7]$, future studies will focus on the evaluation of $\beta$-catenin levels in both the cytoplasm and nucleus, following inhibition/ overexpression of miR-186-5p using in vitro cell models. Apparently, the translocation of $\beta$-catenin from the cytoplasm to the nucleus is where it mediates the transcription of target genes related to EMT and metastasis. Since Bcatenin mediates its effects on EMT markers.

In our microarray analysis, we observed previously published miR-186 validated targets (AKAP12, ROCK1, $P P M 1 B$, and PTTG1) were downregulated as anticipated in RWPE1 stably transfected with miR-186-5p and/or up-regulated in PC-3 cells stably transfected with antimiR-186. Although hundreds of potential miR-186-5p targets were identified in the miR-186-5p depleted PC-3 cells, we focused on AKAP12, a validated target involved 
in prostate cancer. We also focused on AKAP12 because it plays a role in many of cell behaviors (e.g., cell proliferation, colony formation, cell invasion, cell motility, EMT, metastasis, cell invasion, cell cycle arrest, and cell death) that were also modified in our miR-186-5p suppressed metastatic cell models. AKAP12 appears to mediate its effects on cell invasion, presumably through the $\mathrm{p}$-Akt $/ \beta$-catenin the pathway. In future studies, our lab will validate both common and unique targets revealed in the top 30 targets in anti-miR-186-5p transfected PC-3 and miR-186-5p overexpressing prostate cancer cell models cells.

\section{Conclusions}

This is the first report that miR-186-5p is upregulated in PCa patient serum and cell lines. We demonstrated inhibition of miR-186-5p inhibited anchorage-independent cell growth and invasion and reduced pAKT and $\beta$-catenin levels, while increasing tumor suppressor AKAP12. Overall, our data suggest miR-186-5p may function in an oncogenic capacity and serve as a potential prognostic tool and therapeutic target in PCa. Lastly, future studies will elucidate how the miR-186-5p-AKAP12 axis and other miR-186-5p targets play a role in prostate cancer using in vitro and in vivo models.

\section{Additional files}

Additional file 1 Table S1. De-identified demographic and clinicopathological data. Clinical data and serum from 15 men diagnosed with prostate cancer and five disease-free individuals were obtained from the BioServe Biotechnologies Biorepository (Beltsville, MD). Subjects were selfidentified as European American males. There were no significant differences in median age between cases and controls $(p=0.726)$. Among men diagnosed with prostate cancer, $60 \%$ were diagnosed with adenocarcinoma, $66.7 \%$ were smokers, and $73.3 \%$ received two or more therapies. Relative to controls, cases had higher median serum PSA level $(\mathrm{ng} / \mathrm{ml})(p=0.048)$ and BMI $(p=0.225)$ values. (DOCX 63 kb)

Additional file $\mathbf{2}$ Table S2. Differentially expressed human miRNAs in serum from PCa patients. Relative to disease-free individuals, human miRNAs were down-regulated (fold change $\leq-1.5$ ) and up-regulated (fold change $\geq 1.5$ ) in PCa patients when compared to disease-free individuals based on Taqman Human MicroRNA Array data ( $p$-value $\leq 0.05$ ). Global normalization of miRNA profiles identified 26 differentially expressed human miRNAs ( 9 downregulated and 17 up-regulated) in the serum from patients diagnosed with tumor stage I $(n=5)$, III $(n=5)$ and IV $(n=5)$ relative to disease-free individuals $(n=5)$. miRNAs (miRs-106b-5p, - 186-5p, -302b-3p, - 342-3p, -520e, - 885$5 \mathrm{p}$ ), highlighted in gray, represent targets that survived multiple hypothesis testing (FDR $p$-value $\leq 0.05)$. (DOCX $19 \mathrm{~kb}$ )

Additional file 3 Figure S1. Transient and stable miR-186-5p inhibition and overexpression in prostate cancer and normal epithelial cells. miR-186-5p expression was measured following 24-48 h transient post-transfection and stable transfection using qRT-PCR. A) Following transient transfection of cell models with miR-186-5p inhibitor, miR-186-5p was reduced by $33-73 \%$ in PC-3 ( $p=0.0002)$, MDA-PCA-2b $(p=0.0061)$ and LNCaP $(p=0.0381)$ cells. B) Ectopic expression of miR-186-5p in PC-3 ( $p=0.0002)$, MDA-PCA-2b ( $p=$ $0.0061)$ and LNCaP $(p=0.0381)$ cells transiently transfected with miR-186-5p mimic. C) MiR-186-5p expression was reduced by $30 \%$ in PC-3 cells stably transfected with pcDNA-DEST-47-anti-miR-186 compared to pcDNA-DEST-47 (empty vector) ( $p=0.0022$ ). MiR-186-5p was up-regulated by 2.55 -fold in RWPE1 cells stably transfected with pCDNA-DEST-47-miR-186 mimic construct compared to the empty vector control $(p=0.0019)$. Data was quantitated from three independent experiments and are represented as mean fold change \pm S.D. $\left({ }^{* *} p\right.$-value $<0.005,{ }^{* * *} p$-value $\left.<0.007\right)$. (TIFF $\left.1824 \mathrm{~kb}\right)$

Additional file 4 Table S3. Aberrant gene expression in miR-186-5p inhibited PC-3 and miR-186-5p overexpressing RWPE1 cells. Microarray gene list was restricted to genes down-regulated in RWPE1 (fold change $\leq-1.2$ ) and up-regulated in PC-3 cells (fold change $\geq 1.2$ ). Analysis revealed a downregulation of 493 transcripts in RWPE1 cells and up-regulation of 547 transcripts in PC-3 cells. Genes in bold represent previously validated miR-186-5p targets. Moreover, genes were highlighted gray if modified in both RWPE1 with ectopic expression of miR-186-5p and miR-186-5p inhibited PC-3 cells. (DOCX 81 kb)

Additional file $\mathbf{5}$ Figure S2. Up-regulation of AKAP12 in PC-3 cells and PAKT in HEK 293 T cells. A) Total RNA was collected from PC-3 cells transfected with miR-186-5p inhibitor and scramble control $72 \mathrm{~h}$ post-transfection. AKAP12 transcript expression was increased by 1.7-fold in transient miR-186-5p inhibited PC -3 cells relative to negative controls $(p=0.0597)$. B) Protein lysate (35 $\mu \mathrm{g}$ ) was collected from HEK 293 T cells transfected with miR-186-5p mimic and scramble control $72 \mathrm{~h}$ post-transfection. pAKT expression was enhanced by 1.67-fold increase via miR-186-5p overexpression in HEK 293 T cells ( $p=$ $0.196)$. Data was quantitated from at least $2-3$ independent experiments and are represented as mean \pm S.D. (TIFF $457 \mathrm{~kb}$ )

\section{Abbreviations}

AKAP12: A-kinase anchor protein 12=AKAP12; BMI: Body mass index = BMl; CDNA: Complementary DNA; CTBNB1: $\beta$-catenin; EMT: Epithelial

mesenchymal transition; miRs or miRNAs: MicroRNAs; pAKT: PhosphorylatedAKT serine/threonine-protein kinase; PCa: Prostate cancer; PKA: Protein kinase A; PKC: Protein kinase C; PSA: Prostate serum antigen; qRT-PCR: Quantitative Real-time PCR; S.D.: Standard deviation

\section{Acknowledgements}

We would like to acknowledge Dr. Savi Apparta who formerly worked in the Department of Bioinformatics and Biostatistics in the School of Public Health and Information Science at the University of Louisville for her work on the statistical analysis of the Taqman Human microRNA array profiles. We would like to thank Dr. Shahriar Koochekpour his gracious donation of prostate cancer cell lines and Dr. Trinath Das for his consultation on miRNA functional analyses.

\section{Funding}

"Our Highest Potential" in Cancer Research Endowment to Dr. LaCreis R. Kidd and the NCI R25 Cancer Education Grant to Drs. David Hein and LaCreis R. Kidd (CA134283) supported this work. Also, part of this work was performed with the assistance of Sabine Waigel and Vennila Arumugam in the University of Louisville Genomics Core Facility, which is supported by NIH P20GM103436 (KY IDeA Networks of Biomedical Research Excellence), NIH P30GM106396 (UofL James Graham Brown Cancer Center Phase III COBRE), the James Graham Brown Foundation, and user fees. Funding sources had no role in the study design, collection, analysis or interpretation of the data, writing the manuscript, or the decision to submit the paper for publication.

\section{Availability of data and materials}

The datasets used and analyzed in the current study would be available from the corresponding author upon request.

\section{Authors' contributions}

DZR wrote the 1st draft of the manuscript and all authors critically revised the manuscript for important intellectual content. DZJ, GC, MLS, SS, KH and AR designed, performed or optimized the cell proliferation, or colony formation, or cell invasion assays. DZJ, SB, LG designed, performed or optimized the serum based miRNA analyses. DZ and LRK performed or designed the studies for miR-186-5p gene target identification of prostate cancer cell lines. DZR, LRK, JP, $S R$, and GB were involved with the statistical or bioinformatics analysis. DZJ, MLS, SS, KH, GC, KH, and AR designed, performed, or optimized the GRT-PCR assays or western blots. All authors' have made substantial contributions to the conception or study design, or acquisition of data, or analysis and interpretation of data. In addition, each author has participated sufficiently in the work to take public responsibility for appropriate portions of the content. All authors have agreed to be accountable for all aspects of the work to ensure timely investigation and resolve of any questions related to the accuracy or integrity 
of any part of the work. All authors have read, critically reviewed and approved the final manuscript.

\section{Ethics approval and consent to participate}

Personal identifiers were not transferred or transmitted along with biospecimens or demographic, lifestyle, and clinico-pathological data. De-identified samples were obtained from BioServe Biotechnologies Biorepository (Beltsville, MD). The current study met the criteria for exemption under CFR 46.101 (b) (4) from 45 CFR part 46 requirement, since it involved the use of de-identified serum samples and associated patient characteristics data. The current study on the role of deidentified serum-based miRNAs received ethics approval and waived the requirement for a signed consent under the University of Louisville's Institutional Review Board protocol number 201.07.

The study used all patient-derived cells in accordance with the University of Louisville's Institutional Biosafety Committee under protocol (IBC 15-057). The current study predominantly used human cell lines available from the ATCC, which is a publically available repository. Any information known about the ATCC cell lines are publically available and not considered as human subjects research under $\mathrm{HHS}$ regulations at 45 CFR Part 46. Research that proposes the use of human cell lines available from the American Type Culture Collection or a similar repository is not considered human subjects research because the cells are publicly available and all of the information known about the cell lines (perhaps, including the donor) is also publicly available.

\section{Consent for publication}

Not applicable.

\section{Competing interests}

The authors declare that they have no competing interests.

\section{Publisher's Note}

Springer Nature remains neutral with regard to jurisdictional claims in published maps and institutional affiliations.

\section{Author details}

'Department of Pharmacology and Toxicology, University of Louisville School of Medicine, Louisville, KY 40292, USA. ${ }^{2}$ James Graham Brown Cancer Center, University of Louisville School of Medicine, Louisville, USA. ${ }^{3}$ Department of Pharmaceutical Sciences, Skaggs School of Pharmacy and Pharmaceutical Sciences, University of Colorado, Denver, USA. ${ }^{4}$ Division of Gastroenterology and Hepatology, University of Louisville School of Medicine, Louisville, USA. ${ }^{5}$ Department of Biomedical Informatics, The Ohio State University, Columbus, USA. ${ }^{6}$ Department of Biochemistry and Molecular Genetics, University of Louisville School of Medicine, Louisville, USA. D. Department of Bioinformatics and Biostatistics, University of Louisville School of Public Health and Information Science, Louisville, USA. ${ }^{8}$ Department of Cancer Epidemiology, $\mathrm{H}$. Lee Moffitt Cancer Center and Research Institute, Tampa, USA.

\section{Received: 14 August 2017 Accepted: 20 March 2018} Published online: 13 April 2018

\section{References}

1. Society AC. Cancer facts and figures 2018. In. Atlanta: American Cancer Society; 2018.

2. Society AC. Cancer treatment and survivorship facts and figures 2016-2017. Altanta: American Cancer Society; 2016.

3. Pienta KJ, Loberg R. The "emigration, migration, and immigration" of prostate cancer. Clin Prostate Cancer. 2005;4(1):24-30.

4. Saldanha G, Ghura V, Potter L, Fletcher A. Nuclear beta-catenin in basal cell carcinoma correlates with increased proliferation. $\mathrm{Br} J$ Dermatol. 2004:151(1):157-64.

5. Hassanein AM, Glanz SM, Kessler HP, Eskin TA, Liu C. Beta-catenin is expressed aberrantly in tumors expressing shadow cells. Pilomatricoma, craniopharyngioma, and calcifying odontogenic cyst. Am J Clin Pathol. 2003;120(5):732-6.

6. Tordonato C, Di Fiore PP, Nicassio F. The role of non-coding RNAs in the regulation of stem cells and progenitors in the normal mammary gland and in breast tumors. Front Genet. 2015;6:72.
7. Ellison DW, Onilude OE, Lindsey JC, Lusher ME, Weston CL, Taylor RE, Pearson AD, Clifford SC. Beta-catenin status predicts a favorable outcome in childhood medulloblastoma: the United Kingdom Children's Cancer study group brain tumour committee. J Clin Oncol. 2005:23(31):7951-7.

8. Cha YJ, Lee JH, Han HH, Kim BG, Kang S, Choi YD, Cho NH. MicroRNA alteration and putative target genes in high-grade prostatic intraepithelial neoplasia and prostate cancer: STAT3 and ZEB1 are upregulated during prostate carcinogenesis. Prostate. 2016;76(10):937-47.

9. Ren Q, Liang J, Wei J, Basturk O, Wang J, Daniels G, Gellert LL, Li Y, Shen Y, Osman I, et al. Epithelial and stromal expression of miRNAs during prostate cancer progression. Am J Transl Res. 2014;6(4):329-39.

10. Mihelich BL, Maranville JC, Nolley R, Peehl DM, Nonn L. Elevated serum microRNA levels associate with absence of high-grade prostate cancer in a retrospective cohort. PLoS One. 2015;10(4):e0124245.

11. Brase JC, Wuttig D, Kuner R, Sultmann $H$. Serum microRNAs as non-invasive biomarkers for cancer. Mol Cancer. 2010;9:306

12. Vanacore D, Boccellino M, Rossetti S, Cavaliere C, D'Aniello C, Di Franco R, Romano FJ, Montanari M, La Mantia E, Piscitelli R, et al. Micrornas in prostate cancer: an overview. Oncotarget. 2017;8(30):50240-51.

13. Jia W, Wu Y, Zhang Q, Gao G, Zhang C, Xiang Y. Identification of four serum microRNAs from a genome-wide serum microRNA expression profile as potential non-invasive biomarkers for endometrioid endometrial cancer. Oncol Lett. 2013;6(1):261-7.

14. Myatt SS, Wang J, Monteiro LJ, Christian M, Ho KK, Fusi L, Dina RE, Brosens JJ, Ghaem-Maghami S, Lam EW. Definition of microRNAs that repress expression of the tumor suppressor gene FOXO1 in endometrial cancer. Cancer Res. 2010;70(1):367-77.

15. Zhou L, Qi X, Potashkin JA, Abdul-Karim FW, Gorodeski Gl. MicroRNAs miR186 and miR-150 down-regulate expression of the pro-apoptotic purinergic $\mathrm{P} 2 \mathrm{X} 7$ receptor by activation of instability sites at the $3^{\prime}$-untranslated region of the gene that decrease steady-state levels of the transcript. J Biol Chem. 2008:283(42):28274-86

16. Zhang Y, Li M, Wang H, Fisher WE, Lin PH, Yao Q, Chen C. Profiling of 95 microRNAs in pancreatic cancer cell lines and surgical specimens by realtime PCR analysis. World J Surg. 2009;33(4):698-709.

17. Zhang ZL, Bai ZH, Wang XB, Bai L, Miao F, Pei HH. miR-186 and 326 predict the prognosis of pancreatic ductal adenocarcinoma and affect the proliferation and migration of Cancer cells. PLoS One. 2015;10(3):e0118814.

18. Zhao BS, Liu SG, Wang TY, Ji YH, Qi B, Tao YP, Li HC, Wu XN. Screening of MicroRNA in patients with esophageal Cancer at same tumor node metastasis stage with different prognoses. Asian Pac J Cancer Prev. 2013; 14(1):139-43.

19. Qi M, Huang X, Zhou L, Zhang J. Identification of differentially expressed microRNAs in metastatic melanoma using next-generation sequencing technology. Int J Mol Med. 2014;33(5):1117-21.

20. Yang J, Yuan D, Li J, Zheng S, Wang B. miR-186 downregulates protein phosphatase PPM1B in bladder cancer and mediates G1-S phase transition. Tumour Biol. 2016;37(4):4331-41.

21. Zhu X, Shen H, Yin X, Long L, Xie C, Liu Y, Hui L, Lin X, Fang Y, Cao Y, et al. miR-186 regulation of Twist1 and ovarian cancer sensitivity to cisplatin. Oncogene. 2016;35(3):323-32.

22. Cai J, Wu J, Zhang H, Fang L, Huang Y, Yang Y, Zhu X, Li R, Li M. miR-186 downregulation correlates with poor survival in lung adenocarcinoma, where it interferes with cell-cycle regulation. Cancer Res. 2013;73(2):756-66.

23. Li H, Yin C, Zhang B, Sun Y, Shi L, Liu N, Liang S, Lu S, Liu Y, Zhang J, et al. PTTG1 promotes migration and invasion of human non-small cell lung cancer cells and is modulated by miR-186. Carcinogenesis. 2013;34(9):2145-55.

24. Cui G, Cui M, Li Y, Liang Y, Li W, Guo H, Zhao S. MiR-186 targets ROCK1 to suppress the growth and metastasis of NSCLC cells. Tumour Biol. 2014;35(9):8933-7.

25. Ye J, Zhang Z, Sun L, Fang $Y, X u$ X, Zhou G. miR-186 regulates chemosensitivity to paclitaxel via targeting MAPT in non-small cell lung cancer (NSCLC). Mol BioSyst. 2016;12(11):3417-24

26. Dong $Y$, Jin X, Sun Z, Zhao Y, Song X. MiR-186 inhibited migration of NSCLC via targeting cdc42 and effecting EMT process. Mol Cells. 2017:40(3):195-201.

27. Wang $H$, Shen $Q$, Zhang $X$, Yang $C$, Cui S, Sun $Y$, Wang L, Fan X, Xu S. The long non-coding RNA XIST controls non-small cell lung Cancer proliferation and invasion by modulating miR-186-5p. Cell Physiol Biochem. 2017;41(6):2221-9.

28. Ambs S, Prueitt RL, Yi M, Hudson RS, Howe TM, Petrocca F, Wallace TA, Liu CG, Volinia S, Calin GA, et al. Genomic profiling of microRNA and messenger 
RNA reveals deregulated microRNA expression in prostate cancer. Cancer Res. 2008;68(15):6162-70.

29. Erdmann K, Kaulke K, Thomae C, Huebner D, Sergon M, Froehner M, Wirth MP, Fuessel $\mathrm{S}$. Elevated expression of prostate cancer-associated genes is linked to down-regulation of microRNAs. BMC Cancer. 2014;14:82.

30. Hua X, Xiao Y, Pan W, Li M, Huang X, Liao Z, Xian Q, Yu L. miR-186 inhibits cell proliferation of prostate cancer by targeting GOLPH3. Am J Cancer Res. 2016;6(8):1650-60.

31. Zhao X, Wang Y, Deng R, Zhang H, Dou J, Yuan H, Hou G, Du Y, Chen Q, Yu J. miR186 suppresses prostate cancer progression by targeting Twist1. Oncotarget. 2016;7(22):33136-51.

32. Lu S, Wang MS, Chen PJ, Ren Q, Bai P. miRNA-186 inhibits prostate cancer cell proliferation and tumor growth by targeting YY1 and CDK6. Exp Ther Med. 2017;13(6):3309-14.

33. Chen X, Ba Y, Ma L, Cai X, Yin Y, Wang K, Guo J, Zhang Y, Chen J, Guo X, et al. Characterization of microRNAs in serum: a novel class of biomarkers for diagnosis of cancer and other diseases. Cell Res. 2008;18(10):997-1006.

34. Luu HN, Lin HY, Sorensen KD, Ogunwobi OO, Kumar N, Chornokur G, Phelan C, Jones D, Kidd L, Batra J, et al. miRNAs associated with prostate cancer risk and progression. BMC Urol. 2017;17(1):18.

35. Smyth GK. Bioinformatics and computational biology solutions using $\mathrm{R}$ and Bioconductor. New York: Springer; 2005.

36. Smyth GK. Linear models and empirical bayes methods for assessing differential expression in microarray experiments. Stat Appl Genet Mol Biol. 2004;3:Article3.

37. Terzuoli E, Donnini S, Finetti F, Nesi G, Villari D, Hanaka H, Radmark O, Giachetti A, Ziche M. Linking microsomal prostaglandin E Synthase-1/PGE-2 pathway with miR-15a and -186 expression: novel mechanism of VEGF modulation in prostate cancer. Oncotarget. 2016;7(28):44350-64.

38. McCubrey JA, Rakus D, Gizak A, Steelman LS, Abrams SL, Lertpiriyapong K, Fitzgerald TL, Yang LV, Montalto G, Cervello M, et al. Effects of mutations in Wnt/beta-catenin, hedgehog, notch and PI3K pathways on GSK-3 activitydiverse effects on cell growth, metabolism and cancer. Biochim Biophys Acta. 2016;1863(12):2942-76.

39. Akakura S, Huang C, Nelson PJ, Foster B, Gelman IH. Loss of the SSeCKS/ Gravin/AKAP12 gene results in prostatic hyperplasia. Cancer Res. 2008; 68(13):5096-103.

40. Kojima S, Goto Y, Naya Y. The roles of microRNAs in the progression of castration-resistant prostate cancer. J Hum Genet. 2017;62(1):25-31.

41. Huo D, Clayton WM, Yoshimatsu TF, Chen J, Olopade Ol. Identification of a circulating microRNA signature to distinguish recurrence in breast cancer patients. Oncotarget. 2016;7(34):55231-48.

42. Ries J, Vairaktaris E, Agaimy A, Kintopp R, Baran C, Neukam FW, Nkenke E. miR-186, miR-3651 and miR-494: potential biomarkers for oral squamous cell carcinoma extracted from whole blood. Oncol Rep. 2014;31(3):1429-36.

43. Yao K, He L, Gan Y, Zeng Q, Dai Y, Tan J. MiR-186 suppresses the growth and metastasis of bladder cancer by targeting NSBP1. Diagn Pathol. 2015;10:146.

44. Liu Z, Zhang G, Yu W, Gao N, Peng J. miR-186 inhibits cell proliferation in multiple myeloma by repressing Jagged1. Biochem Biophys Res Commun. 2016;469(3):692-7.

45. Honegger A, Schilling D, Bastian S, Sponagel J, Kuryshev V, Sultmann H, Scheffner M, Hoppe-Seyler K, Hoppe-Seyler F. Dependence of intracellular and exosomal microRNAs on viral E6/E7 oncogene expression in HPVpositive tumor cells. PLoS Pathog. 2015;11(3):e1004712.

46. He W, Feng J, Zhang Y, Wang Y, Zang W, Zhao G. microRNA-186 inhibits cell proliferation and induces apoptosis in human esophageal squamous cell carcinoma by targeting SKP2. Lab Investig. 2016;96(3):317-24.

47. Cao C, Sun D, Zhang L, Song L. miR-186 affects the proliferation, invasion and migration of human gastric cancer by inhibition of Twist1. Oncotarget. 2016;7(48):79956-63.

48. Ruan T, He X, Yu J, Hang Z. MicroRNA-186 targets yes-associated protein 1 to inhibit hippo signaling and tumorigenesis in hepatocellular carcinoma. Oncol Lett. 2016;11(4):2941-5.

49. Jiao D, Wu M, Ji L, Liu F, Liu Y. microRNA-186 suppresses cell proliferation and metastasis through targeting Sentrin specific protease 1 in renal cell carcinoma. Oncol Res. 2018;26(2):249-59.

50. Wang F, Jiang H, Wang $\mathrm{S}$, Chen B. Dual functional MicroRNA-186-5p targets both FGF2 and RelA to suppress tumorigenesis of glioblastoma Multiforme. Cell Mol Neurobiol. 2017;37(8):1433-42.

51. Islam F, Gopalan V, Vider J, Wahab R, Ebrahimi F, Lu CT, Kasem K, Lam AKY. MicroRNA-186-5p overexpression modulates colon cancer growth by repressing the expression of the FAM134B tumour inhibitor. Exp Cell Res. 2017:357(2):260-70

52. Gelman IH. Suppression of tumor and metastasis progression through the scaffolding functions of SSeCKS/Gravin/AKAP12. Cancer Metastasis Rev. 2012;31(3-4):493-500

53. Gelman IH. Emerging roles for SSeCKS/Gravin/AKAP12 in the control of cell proliferation, Cancer malignancy, and Barriergenesis. Genes Cancer. 2010; 1(11):1147-56.

54. Su B, Bu Y, Engelberg D, Gelman IH. SSeCKS/Gravin/AKAP12 inhibits cancer cell invasiveness and chemotaxis by suppressing a protein kinase C- Raf/ MEK/ERK pathway. J Biol Chem. 2010;285(7):4578-86.

55. Xia W, Unger P, Miller L, Nelson J, Gelman IH. The Src-suppressed C kinase substrate, SSeCKS, is a potential metastasis inhibitor in prostate cancer. Cancer Res. 2001;61 (14):5644-51.

56. Xia W, Ni J, Zhuang J, Qian L, Wang P, Wang J. MiR-103 regulates hepatocellular carcinoma growth by targeting AKAP12. Int J Biochem Cell Biol. 2016;71:1-11.

57. Goeppert B, Schmezer P, Dutruel C, Oakes C, Renner M, Breinig M, Warth A, Vogel MN, Mittelbronn M, Mehrabi A, et al. Down-regulation of tumor suppressor a kinase anchor protein 12 in human hepatocarcinogenesis by epigenetic mechanisms. Hepatology. 2010;52(6):2023-33.

58. Gelman IH, Gao L. SSeCKS/Gravin/AKAP12 metastasis suppressor inhibits podosome formation via RhoA- and Cdc42-dependent pathways. Mol Cancer Res. 2006;4(3):151-8.

59. Wise HM, Hermida MA, Leslie NR. Prostate cancer, PI3K, PTEN and prognosis. Clin Sci (Lond). 2017:131(3):197-210.

60. Eastman $\mathrm{Q}$, Grosschedl R. Regulation of LEF-1/TCF transcription factors by Wnt and other signals. Curr Opin Cell Biol. 1999;11(2):233-40.

61. Kypta RM, Waxman J. Wnt/beta-catenin signalling in prostate cancer. Nat Rev Urol. 2012;9(8):418-28.

62. Dulinska-Litewka J, McCubrey JA, Laidler P. Increased Akt signaling resulting from the loss of androgen responsiveness in prostate cancer. Curr Med Chem. 2013;20(1):144-57.

63. Wu TT, Sikes RA, Cui Q, Thalmann GN, Kao C, Murphy CF, Yang H, Zhau HE, Balian G, Chung LW. Establishing human prostate cancer cell xenografts in bone: induction of osteoblastic reaction by prostate-specific antigen-producing tumors in athymic and SCID/bg mice using LNCaP and lineage-derived metastatic sublines. Int J Cancer. 1998;77(6):887-94.

\section{Submit your next manuscript to BioMed Central and we will help you at every step:}

- We accept pre-submission inquiries

- Our selector tool helps you to find the most relevant journal

- We provide round the clock customer support

- Convenient online submission

- Thorough peer review

- Inclusion in PubMed and all major indexing services

- Maximum visibility for your research

Submit your manuscript at www.biomedcentral.com/submit
Biomed Central 